\title{
EGO DEPLETION: A POTENTIAL COST ASSOCIATED WITH ACTING COUNTER DISPOSITIONALLY
}

\author{
A thesis submitted to \\ the Faculty of Graduate Studies and Research \\ in Partial Fulfillment of the requirements for the degree \\ Master of Arts
}

by

Maya S. Santoro

Department of Psychology

Carleton University

June 2009

(C2009 Maya Santoro 


$\begin{array}{ll}\begin{array}{l}\text { Library and Archives } \\ \text { Canada }\end{array} & \begin{array}{l}\text { Bibliothèque et } \\ \text { Archives Canada }\end{array} \\ \begin{array}{l}\text { Published Heritage } \\ \text { Branch }\end{array} & \begin{array}{l}\text { Direction du } \\ \text { Patrimoine de l'édition }\end{array} \\ \begin{array}{l}\text { 395 Wellington Street } \\ \text { Ottawa ON K1A ON4 } \\ \text { Canada }\end{array} & \begin{array}{l}395, \text { rue Wellington } \\ \text { Ottawa ON K1A ON4 } \\ \text { Canada }\end{array}\end{array}$

Your file Votre refférence

ISBN: 978-0-494-58426-2

Our file Notre refference

ISBN: $978-0-494-58426-2$

NOTICE:

The author has granted a nonexclusive license allowing Library and Archives Canada to reproduce, publish, archive, preserve, conserve, communicate to the public by telecommunication or on the Internet, loan, distribute and sell theses worldwide, for commercial or noncommercial purposes, in microform, paper, electronic and/or any other formats.

The author retains copyright ownership and moral rights in this thesis. Neither the thesis nor substantial extracts from it may be printed or otherwise reproduced without the author's permission.
AVIS:

L'auteur a accordé une licence non exclusive permettant à la Bibliothèque et Archives Canada de reproduire, publier, archiver, sauvegarder, conserver, transmettre au public par télécommunication ou par l'Internet, prêter, distribuer et vendre des thèses partout dans le monde, à des fins commerciales ou autres, sur support microforme, papier, électronique etJou autres formats.

L'auteur conserve la propriété du droit d'auteur et des droits moraux qui protège cette thèse. $\mathrm{Ni}$ la thèse ni des extraits substantiels de celle-ci ne doivent être imprimés ou autrement reproduits sans son autorisation.
In compliance with the Canadian Privacy Act some supporting forms may have been removed from this thesis.

While these forms may be included in the document page count, their removal does not represent any loss of content from the thesis.
Conformément à la loi canadienne sur la protection de la vie privée, quelques formulaires secondaires ont été enlevés de cette thèse.

Bien que ces formulaires aient inclus dans la pagination, il n'y aura aucun contenu manquant. 


\begin{abstract}
Recent research has demonstrated that acting extraverted increases positive affect for both introverts and extraverts (McNiel \& Fleeson, 2006). McNiel and Fleeson (2006) suggested that encouraging extraverted behaviour may be an effective method to increase well-being. However, one first needs to understand the factors that drive and limit individuals from acting extraverted. The present study examined the hypothesis that introverts self-regulate their behaviour to act extraverted, thereby inducing cognitive fatigue. Participants $(n=129)$ engaged in an interview where they were instructed to act introverted, extraverted, or naturally. Cognitive fatigue was assessed using Stroop task performance and change in blood glucose. The results revealed that acting counterdispositionally was not related to decreased blood glucose; however, it was associated with slower Stroop reaction times. The Stroop findings support the hypothesis that acting counter-dispositionally is depleting. Identifying this cost is important, because cognitive fatigue negatively affects self-regulatory functioning across many domains.
\end{abstract}




\section{Acknowledgements}

"Sometimes our light goes out but is blown into flame by another human being. Each of us owes deepest thanks to those who have rekindled this light."- Albert Schweitzer

I owe many thanks to those who helped keep my fire burning throughout this process. I would like to start by thanking my supervisor and mentor, Dr. John Zelenski, who took a chance on me in my undergraduate years and accepted me into his lab. His help throughout these past few years has been immeasurable and my gratitude immense.

I would like to thank my family and close friends for their endless support throughout the entirety of my university career. You have all helped me so much that there are not pages enough to express how grateful I am and how much you all mean to me. You all make me a stronger, better person and you are all loved and appreciated greatly.

There were a number of people who were involved in the collection of data for this study. I would like to thank all the members of Team Super Awesome Amazing: Rosina, Fatima, Rene, Sarah, Nathalie, Cassandra, Leah, and Jen. I most definitely would not have been able to complete this without all of your hard work and dedication. As well, my thanks go out to my prospectus and thesis defense committee for their time, commitment, and many words of wisdom. Lastly, I would like to send my thanks out to Etelle in the department for all of her help and guidance throughout this process.

Thank you kindly. 


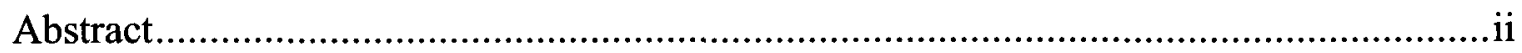

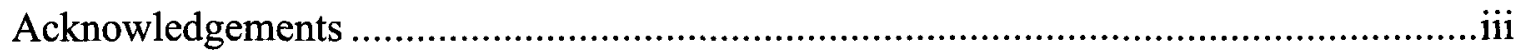

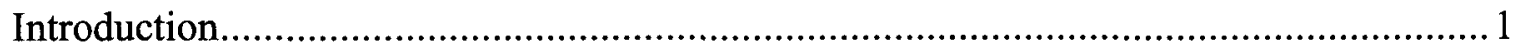

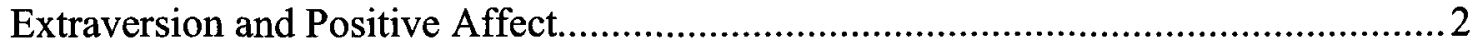

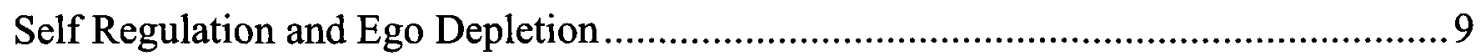

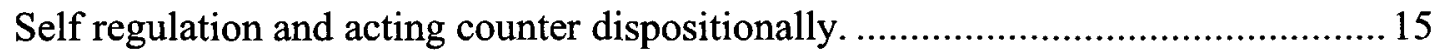

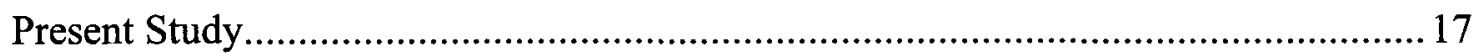

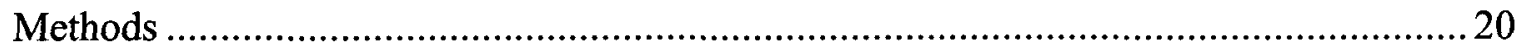

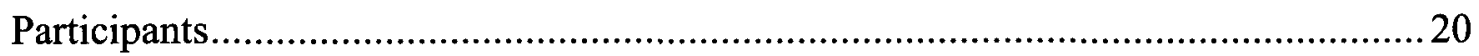

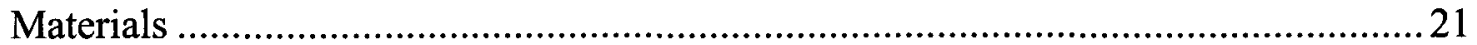

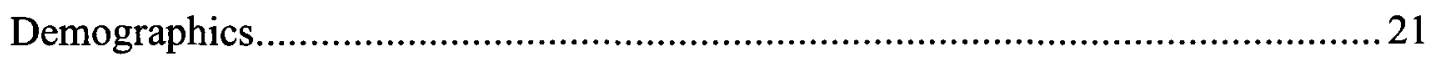

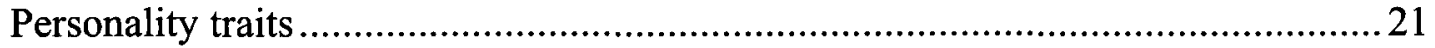

Interview.

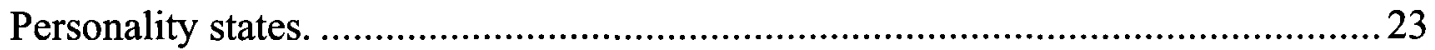

Positive affect, Negative Affect, and Enjoyment ..................................................23

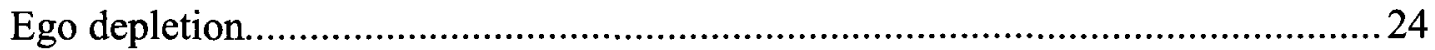

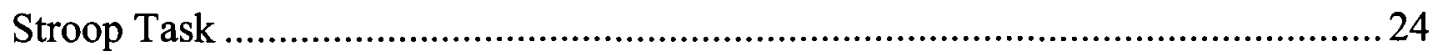

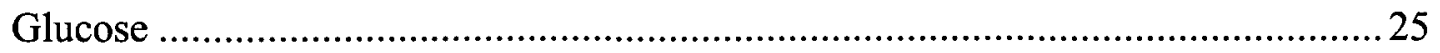

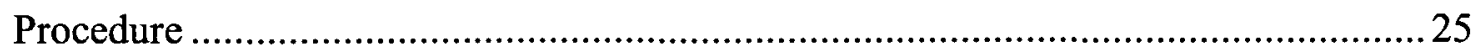

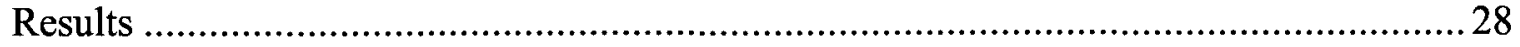

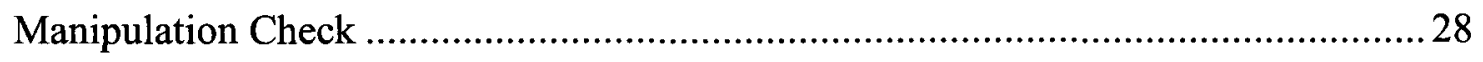

Hypothesis 1: State Extraversion and Positive Affect.................................................. 31 
Hypothesis 2: Acting Counter-Dispositionally leads to Cognitive Fatigue.

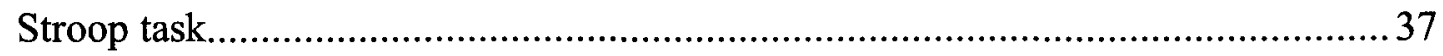

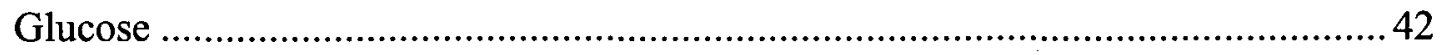

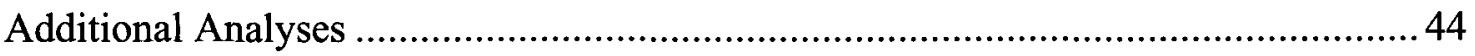

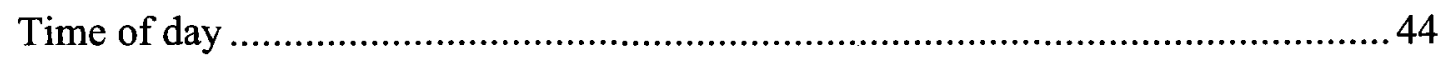

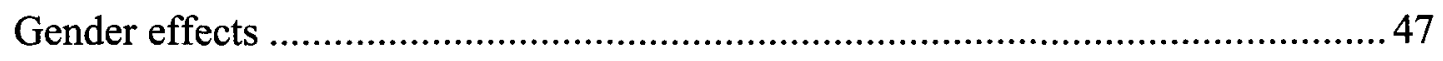

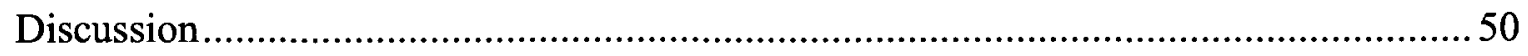

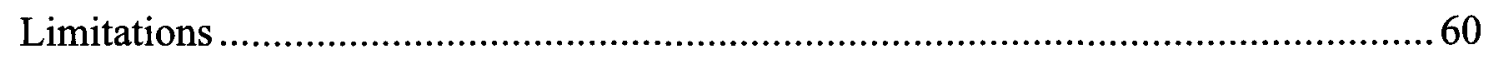

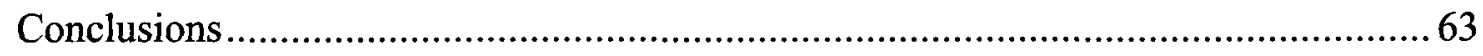

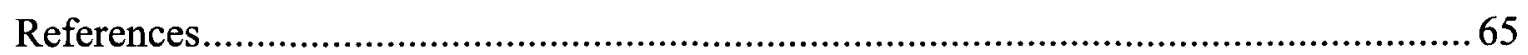




\section{List of Tables}

Table 1 Ratings of mean extraverted behaviour across condition for each rater... 29

Table 2 Intercorrelations between the dependent measures................... 30

Table 3 Mean Number of Errors Following Interview Session................. 38

Table 4 Mean Reaction Times (in milliseconds) Following the Interview........ 41

Table 5 Mean glucose levels before and after the interview.................. 43 


\section{List of Figures}

Figure 1 Mean extraverted behaviour as a function of behavioural condition...... 30

Figure 2 Distribution of mean positive affect scores by behavioural condition..... 33

Figure 3 Mean negative affect scores as a function of behavioural condition...... 36

Figure 4 Mean reaction times as a function of condition and disposition......... 40

Figure 5 Mean glucose levels as a function of time of day...................... 46

Figure 6 Mean glucose levels before and after the interview across gender....... 49 


\section{List of Appendices}

Appendix A- Mass Testing Questionnaire ............................................... 78

Appendix B- Informed Consent Form.......................................................... 79

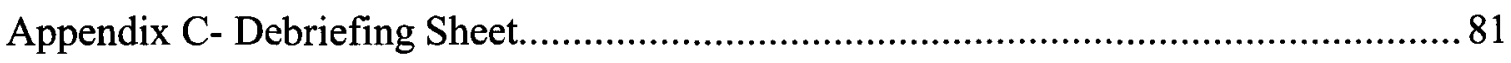

Appendix D- Email for Recruitment ............................................................ 82

Appendix E- Demographics Questionnaire ................................................... 83

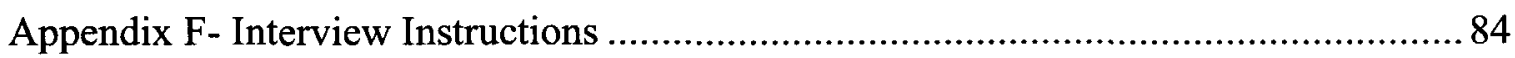

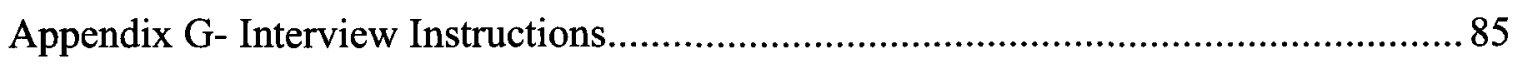

Appendix H- Interview Instructions............................................................ 86

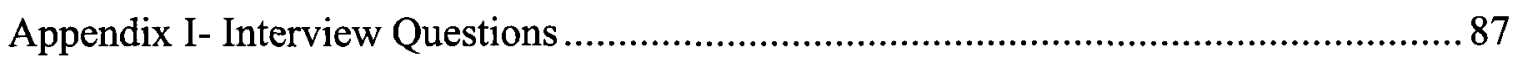

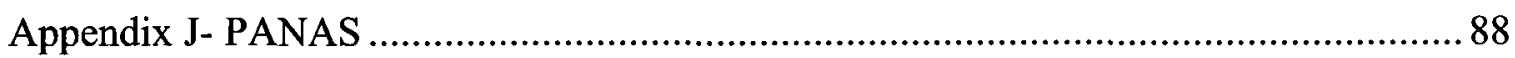

Appendix K- Behaviour Questionnaire .......................................................... 89

Appendix L- Enjoyment Questionnaire........................................................... 90

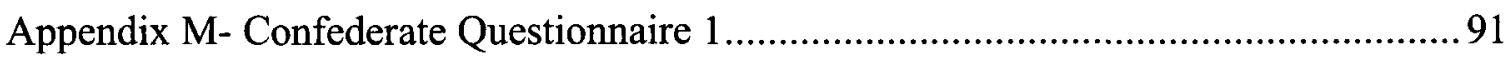

Appendix N - Confederate Questionnaire 2 ................................................. 92 
EGO DEPLETION: A POTENTIAL COST ASSOCIATED WITH ACTING COUNTER

\section{DISPOSITIONALLY}

\section{Introduction}

Within the realm of Psychology, there is a wide body of literature dedicated to the study of happiness and well-being. One area of research has focused primarily on the relationship between stable and enduring personality traits and well-being. For example, research has established that extraversion is positively correlated with happiness (e.g., Lucas \& Fujita, 2000; Rusting \& Larsen, 1995). That is, someone who is described as bold, active, and outgoing tends to be happier than someone who does not possess these characteristics. Although the relationship between trait extraversion and positive affect has been widely documented, recent findings have suggested that the extraversionpositive affect relationship is not limited to dispositional extraverts.

Recent studies have shown that behaving extraverted in the moment is associated with heightened positive affect, regardless of underlying personality disposition (Fleeson, Malanos, \& Achilles, 2002; McNiel \& Fleeson, 2006; Santoro, 2007). Assuming common desire to experience positive emotions, one might predict that introverted individuals would act extraverted more often in order to experience the increased positive affect. Despite the increased positive affect, there appear to be factors that hold introverts back from acting extraverted.

It could be that regulating behaviour to act out of character is a limiting force. Past research has demonstrated that acts of self-regulation, such as decision making or self presentation, require cognitive energy that becomes depleted with continued use (e.g., Baumeister, 2002; Muraven \& Baumeister, 2000). This implies that any self-regulatory 
act immediately following another will be compromised due to either a lack of, or conservation of, cognitive energy (Schmeichel, Baumeister, \& Vohs, 2003). The present study examined the hypothesis that acting counter to one's personality disposition induces cognitive fatigue, thereby impairing later performance on self-regulatory tasks. Specifically, introverts who are made to act extraverted need to regulate their behaviour to do so, thereby depleting their cognitive resources. The same was expected to be true for extraverts who are made to act introverted. This study may help to explain why introverts are not inclined to act more extraverted, even if the behaviour is related to heightened positive affect.Extraversion and Positive Affect

Extraversion is often studied as a personality trait. That is, research has focused on extraversion as a feature of one's personality that is stable and enduring over time. Studies have examined differences between those who score low and high on trait extraversion. As noted, extraverts are described as bold, active, and outgoing. Conversely, introverts are described as quiet, passive, and less sociable (Fleeson, et al., 2002). Research has established that someone who is extraverted is happier than someone who is introverted (Fry \& Heubeck, 1998). Specifically, trait extraversion is moderately related to positive affect (e.g., Côté, \& Moskowitz, 1998; Lucas \& Fujita, 2000), accounting for between $15 \%$ and $34 \%$ of the variance in positive affect (McNiel $\&$ Fleeson, 2006). This relationship has been documented through spouse ratings (Costa \& McCrae, 1988), across countries (Headey \& Wearing, 1989), in children and adults (Wilson \& Gullone, 1999), as well as in non-human primates (Weiss, King, \& Enns, 2002). Explaining this relationship has been the focus of much research and the importance of this relationship is established by findings that have linked positive affect 
to a variety of optimal outcomes ${ }^{1}$.

There is debate regarding the nature of the relationship between extraversion and positive affect. One view posits that extraversion is indirectly related to positive affect, with social interaction exerting influence. In support of this view, a number of studies have shown that social activity and interaction are predictors of positive affect (e.g., Baumeister, DeWall, Ciarocco, \& Twenge, 2005; Lucas \& Fujita, 2000; McIntyre, Watson, Clark, \& Cross, 1991). As well, extraverts are generally more sociable than introverts.

In line with this view, several studies have suggested that extraverts are happier than introverts because they spend more time in social situations, thus the extraversionpositive affect relationship is mediated by social interaction (Argyle \& Lu, 1990; Pavot, Diener, \& Fujita, 1990; Watson, 1988). An extension of this view is that extraverts are happier because they have a physiological inclination to seek out social situations (Costa \& McCrae, 1980; Larsen \& Ketelaar, 1991; Pavot, et al., 1990). According to this view, extraverts are depicted as individuals who experience a continual state of neurocortical under-arousal, which leads them to seek social stimulation and excitement in order to reach an optimal level of arousal. Social interaction is depicted as stimulating because it leads to activation of the Autonomic Nervous System (Fry \& Heubeck, 1998; Little, 2000; Rusting \& Larsen, 1997). There are a number of studies that support this view.

\footnotetext{
${ }^{1}$ Happy individuals are more successful in most domains of their lives, including relationships, health, and occupation (Lyubomirksy, Diener, \& King, 2005). As well, positive affect is associated with greater creative problem solving (Ashby, Isen, \& Turken, 1999; Daubman, Isen, \& Nowicki, 1987; Fredrickson \& Losada, 2005), predicts higher self-ratings of physical health (Pettit, Kline, Gencoz, Gencoz, \& Joiner, 2001), and seems to decrease one's level of global stress (Folkman \& Moscowitz, 2000; Fredrickson \& Joiner, 2002; Watson, 1988).
} 
However, a study has found that after controlling for amount of social activity, extraverts still report higher levels of positive affect than introverts (Lucas, Le, \& Dyrenforth, 2008).

Along similar lines, there is a theory that level of social interaction is mediated by the over- or under-activation of the Central Nervous System (CNS) (i.e., AugmentingReducing Model; Petrie, 1967). This model has been linked with trait introversion and extraversion. Specifically, those who link trait extraversion to this model propose that extraverts cortically reduce the intensity of incoming sensory information. As such, their CNS is in a chronic state of under-arousal, which they compensate for by seeking out highly stimulating or social surroundings (e.g., Dragutinovich, 1987; Schwerdtfeger, Getzmann, \& Baltissen, 2004). Conversely, introverts are believed to avoid social situations due to a chronically over-activated CNS, because of an amplification of sensory input (e.g., Dragutinovich, 1987; Schwerdtfeger et al., 2004). However, past findings in support of this model are inconsistent, depending on the type of measurement employed (Dragutinovich, 1987; Lolas, Camposano, \& Etcheberrigaray, 1989; Stenberg, Rosen, \& Risenberg, 1988).

Other proponents of an indirect relationship have suggested that extraverts gain more enjoyment from, or are more reactive to, social situations than introverts (Diener, Larsen, \& Emmons, 1984; Lucas, et al., 2000). This relates to the view that the relationship between social interaction and positive affect is moderated by trait extraversion. The research findings pertaining to this view, however, are inconsistent across studies (Lucas, et al., 2008).

In line with this standpoint, Gray (1981) proposed that individuals are equipped 
with two neurologically-based systems that control behaviour when in the presence of reward or punishment. The Behavioural Activation System (BAS) responds to reward by inciting approach behaviour. The Behavioural Inhibition System (BIS) responds more highly to punishment by producing withdrawal behaviour. The theory posits that an individual who is extraverted has a highly activated BAS system compared to someone who is introverted (Rusting \& Larsen, 1997; Fischer, Wik, \& Fredrickson, 1997).

It could be that extraverts are more physiologically inclined to display approachoriented behaviours than introverts (Pavot, Diener, \& Fujita, 1990). This proposed neurophysiological difference between introverts and extraverts has been used to explain the difference in their baseline levels of happiness. It is possible that situational rewards incite more approach behaviour from extraverts and therefore they experience increased positive affect more often than introverts because of their reactivity to social rewards. However, it is also possible that the reward-sensitivity is directly related to positive affect and not dependent on social activity (Lucas, et al., 2008). This is in line with the position that extraversion is directly related to positive affect (Lucas, et al., 2008). According to this position, dispositional extraverts should be happier than introverts in social and nonsocial situations, however, the evidence for this view is mixed (Lucas, et al., 2008; Pavot, Diener, \& Fujita, 1990).

It is possible that the relationship between extraversion and positive affect is a combination of the above propositions. It could be that extraverts spend more time in social situations than introverts, that social situations are inherently pleasant, that extraverts are more reactive to rewards in general, and/or that extraverts enjoy higher baseline levels of positive affect. 
The study of the relationship between positive affect and extraversion has focused primarily on extraversion as a stable and enduring trait. According to Fleeson (2001), personality traits are compositions of distributions of state behaviours over time. Whereas traits are defined as stable and enduring over time, personality states are defined as behaviours that change with time and situation. Fleeson's (2001) Density-Distributions Approach suggests that the most accurate way of measuring personality is to observe changes in a person throughout his or her daily life and create a distribution of his or her behaviours over time. This will produce a frequency distribution of each trait based on an individual's behaviours (Fleeson, 2004). Showing that there is variability in state behaviour over time supports the idea that people oscillate from acting introverted to extraverted (Fleeson, 2007). Even dispositional introverts act extraverted in their daily lives, whether as a result of internal impulses or situational demand. According to this view, trait extraversion and state extraversion will share the same relationship with positive affect, since traits are the composites of behaviours one enacts over time.

Little (2000) has put forth another theoretical approach to understand personality traits, which also accounts for behavioural variation. He posits that there is a dynamic interaction between internal processes and external demand in determining the personality that we portray and enact (Little, 2000; Little, 2006; Little \& Joseph, 2007). In other words, traits are only partly cemented. According to his Free Trait Model, selfexpression can be broken down into three dimensions. There is the first nature or biogenic way of being. This refers to how one acts based on neurophysiological and genetically-driven processes. The second nature, or sociogenic way of being, refers to the way one acts because of socialization (Little \& Joseph, 2007). The third nature, or 
idiogenic way of being, is the way one behaves as a means of reaching personal goals (Little \& Joseph, 2007). He refers to the third nature as the enactment of free traits (Little, 2000). For example, it may benefit introverted individuals to act extraverted during a work presentation in order to impress his or her employer. Both Little's Free Trait Model and Fleeson's Density-Distributions Approach account for the interaction between situation and personality on behaviour.

The Free Trait Model also proposes that acting counter to one's genetic disposition, or first nature, is met with emotional and psychological costs, and, if prolonged, can be followed by impaired health and well being (Little, 2000; Little \& Joseph, 2007). These costs may include cognitive fatigue, failure to maintain the free trait behaviour, and decrements in performance of problem solving and information processing (Little, 2000; Little \& Joseph, 2007). The more discordant behaviour is from the individual's biogenic personality, the more strain this will cause him or her (Little \& Joseph, 2007). According to Little, this is partly because regulating behaviour to act counter to one's natural tendencies affects the autonomic nervous system and immune system (Little, 2000). It seems that although employing the use of free traits can be beneficial for reaching goals, it also involves costs.

In outlining the costs of acting counter to one's biogenic nature, he uses the example of an introvert who acts extraverted as a means of fulfilling a personal project, such as being social at a party to make a good first impression (Little, 2000). He proposes that extraversion, in this case, is a free trait that is called upon to meet his or her goal of making a good first impression on others (Little, 2000). In this example, acting extraverted may help increase the individual's well being in the moment, as well as help 
him or her meet a meaningful goal (Little, 2000). However, an introvert who regulates his or her behaviour to act extraverted will also endure psychological and physiological costs (Little, 2000). For example, the introverted individual may not be able to maintain the extraverted behaviour if the party lasts for a long period of time, or may experience fatigue. This approach to defining personality is largely theoretical. The empirical support for the Free Trait Model is still in the early stages (Little \& Joseph, 2007), and the present study provides an initial empirical test of some aspects of this model.

Personality states or free traits and their relationship with well-being have been the focus of recent preliminary research. Specifically, a few studies have empirically examined the relationship between state extraversion and positive affect. There is evidence to suggest that, like trait extraversion, increased state extraversion is related to increased positive affect (Fleeson, Malanos, \& Achilles, 2002; McNiel \& Fleeson, 2006; Santoro, 2007; Williams, 2006). In a study conducted by McNiel and Fleeson (2006), participants were instructed to behave in either an introverted or extraverted manner during a group discussion. Afterwards, participants in the extraverted condition had significantly higher levels of positive affect than those in the introverted condition. A participant's underlying personality disposition did not interact with his or her behavioural condition, therefore dispositional extraverts and introverts experienced similar increases in positive affect when acting extraverted. The results of this study suggest that if introverts regulate their behaviour to act more extraverted, they will experience increased positive affect while doing so. Additionally, the state extraversionpositive affect relationship has been found outside of the laboratory through experience sampling methodology (Fleeson, et al., 2002). 
McNiel and Fleeson $(2006,546)$ state that "The knowledge that acting extraverted...has affective consequences could inform clinical interventions. For example, effective treatments for individuals with clinical disorders might include encouraging them to act more extraverted." This statement bears the assumption that there are no downsides to acting extraverted for individuals who are not inclined to do so. Before instructing individuals, especially introverts, to behave in an extraverted manner, it is important to ascertain whether or not there are costs associated with doing so. This proposition follows suit with Little's (2000) Free Trait Model, in that it would predict that introverts incur costs due to acting against their first nature.

One potential consequence could be that, when acting extraverted, introverts experience increased negative affect alongside increased positive affect. That is, they may feel happier, yet also more stressed. This possibility was examined within the scope of McNiel and Fleeson's (2006) study and was not supported. Specifically, when acting extraverted, introverted individuals did not experience increased negative affect compared to extraverts. Another potential cost is that regulating behaviour to act counter to one's personality disposition leads to an inherent cost of cognitive fatigue. This line of thought also is consistent with recent studies on self regulation. The present study examined the idea that acting counter dispositionally is cognitively fatiguing.

\section{Self Regulation and Ego Depletion}

Self-regulation, or self-control, refers to the effortful process of controlling and modifying one's own behaviours, cognitions, emotions, and impulses to meet goals (Baumeister, Gailliot, \& DeWall, 2006; Hoyle, 2006). The self-regulatory process is necessary for many daily activities, such as maintaining attention, delaying gratification, 
regulating emotions, managing social impressions, acting counter to one's natural tendencies, planning, and making difficult decisions (Baumeister, Heatherton, \& Tice, 1993; Eisenberg, Spinrad, \& Morris, 2002; Vohs, Ciarocco, \& Baumeister, 2005; Muraven \& Baumeister, 2000; Schmeichel, Baumeister, \& Vohs, 2003). Self-regulation is successful when one adapts to his or her environment and works towards reaching goals (Baumeister \& Heatherton, 1996). Failure is marked by either not adapting to changes in one's environment or not behaving in a manner that is effective in achieving goals (Heatherton \& Baumeister, 1996; Hoyle, 2006). When comparing individuals, those who self-regulate effectively are more likely to have healthier interpersonal relationships, better mental and physical health, employ more effective coping strategies, exhibit less aggression, and perform better academically than individual who do not self-regulate effectively (Baumeister, 2002; Baumeister, Vohs, \&Tice, 2007; Gailliot, Baumeister, DeWall, Maner, Plant, Tice, Brewer, \& Schmeichel, 2007).

Self-regulation seems to require the use of cognitive energy that comes from a limited resource, and which becomes depleted with continued use (Baumeister, 2002; Baumeister, Gailliot, \& DeWall, 2006). The Strength Model proposes that the entire range of self-regulatory acts requires the extraction of cognitive energy from the same inner, limited reserve (Heatherton \& Baumeister, 1996; Muraven \& Baumeister, 2000; Vohs, et al., 2005). Each self-regulatory act uses cognitive energy, thereby depleting the available resource. Regardless of the specific type of task, any self-regulatory act that immediately follows another will be compromised due to a depletion of cognitive energy (Baumeister, 2002; Schmeichel, Baumeister, \& Vohs, 2003). That is, the cognitive energy source is non-specific and limited in supply. This state of depletion has been 
coined Ego Depletion (Baumeister, Bratslasvky, Muraven, \& Tice, 1998), Regulatory Depletion (Muraven, Tice, \& Baumeister, 1998), or Cognitive Fatigue. Depletion is not permanent, but the process of replenishment appears to be slower than the process of depletion (Muraven \& Baumeister, 2000). Proponents of the Strength Model compare self-control or self-regulation to a muscle. Just like a muscle, self-regulatory ability is weakened after prolonged use, yet becomes strengthened over time with continued, longterm exercise (Baumeister, 2002). One can increase his or her store of cognitive energy over time with continued self-regulatory practice. However, each regulatory act will still lead to less cognitive energy available for subsequent regulatory activity.

Research has examined the extent to which the store of cognitive energy becomes depleted after acts of self-regulation or self-control. Each act of self-regulation is believed to use consecutively more cognitive energy until self-regulatory performance is impaired. This proposal comes from studies showing that performance on cognitivelydemanding tasks deteriorates after acts of self-regulation (e.g., Glass, Singer, \& Friedman, 1969; Muraven \& Baumeister, 2000; Schmeichel, Vohs, \& Baumeister, 2003). This notion has been extended to propose that once people reach a relatively low level of cognitive energy, they begin to conserve the remaining amount rather than allowing the store to become fully depleted. Support for this proposition comes from studies showing that ego-depleted participants are able to further regulate their behaviour if they feel they need to, such as in studies where amount of money earned is conditional on level of performance on a second self-regulatory task (e.g., Muraven, 1998).

Many daily activities require effective self-regulation, and cognitively fatigued individuals are less likely to perform these tasks effectively (Lorist, Boksem, \& 
Ridderinkhof, 2005). For example, experimentally-depleted individual are more likely to display aggression (DeWall, Baumeister, Stillman, \& Gailliot, 2007), less able to manage self-presentation (Leary, Nezlek, Downs, Radford-Davenport, Martin, \& McMullen, 1994; Vohs, et al., 2005), and less likely to make difficult decisions, plan effectively, or persist on cognitively challenging tasks (Baumeister, Gailliot, \& DeWall, 2006; Muraven, et al., 1998; Schmeichel, Baumeister, \& Vohs, 2003; Van der Linden, Frese, \& Meijman, 2003; Vohs, Ciarocco, \& Baumeister, 2005). They are also less able to control their impulses (e.g., binge drink or eat), suppress stereotyping, and regulate emotions effectively (e.g., Baumeister, Gailliot, \& DeWall, 2006; Crockett, Raffaelli, \& Shen, 2006; Muraven \& Baumeister, 2000).

To date, ego depletion has primarily been assessed with performance measures. For example, studies have shown that ego-depleted participants persist less on unsolvable tasks (Baumeister, Bratslasvky, Muraven, \& Tice, 1998; Vohs, et al., 2005). In such tasks, an individual must regulate his or her behaviour to continue persevering on a task that cannot be completed. Individuals who are cognitively fatigued have less cognitive energy to employ than those who are not, therefore they persist less on these unsolvable tasks. This depletion is not found when assessing performance on automatic, habitual tasks (Baumeister, 2002; Baumeister, Gailliot, \& DeWall, 2006). The Stroop Task is another measure that has been used to assess cognitive fatigue (e.g., Glass \& Singer, 1972). In this task, an individual is presented with colour words, some of which are written in matching coloured ink, and others that are written with different coloured ink (e.g., the word blue written in blue ink versus the word blue written in red ink). The individual's task is to identify the colour of the word and ignore the written text. For the 
trials where the word and ink are discordant, individuals must override their natural tendency to read the written text in order to respond to the colour of the ink. An individual who is cognitively fatigued shows decrements in performance on the incongruent trials compared to an individual who is not fatigued. This is only the case for the incongruent trials that require self-regulation and not for the congruent trials, which evoke an automatic response. In addition to these measures, Over 50 studies have supported the Strength Model of Ego Depletion, using a number of different techniques (Gailliot \& Baumeister, 2007). The results suggest that self-regulatory activities across areas of one's life draw upon the same limited resource that becomes depleted with continued use.

Ego depletion, or cognitive fatigue, is a process that is not fully understood. The Strength Model has been used to help explain the decrements in self-regulatory performance. Recent research, however, has provided some evidence that glucose might be a physiological mechanism partly responsible for self-regulation. Studies show that glucose is the fuel of the brain, which travels through the bloodstream and is metabolized for cognitive use. It also promotes the firing of neurons by acting as their fuel (Gailliot, Baumeister, DeWall, Maner, Plant, Tice, Brewer, \& Schmeichel, 2007; Gailliot \& Baumeister, 2007). Until recently, many have believed that cognitive functioning is not highly affected by regular fluctuations in glucose levels (Booth, 1994). New findings, however, have suggested that fluctuations in glucose affect cognitive performance, especially on cognitively-challenging undertakings (Donohoe \& Benton, 1999). The discovery that normal fluctuations in glucose are related to cognitive performance has directed research focus towards the examination of the effects of glucose on cognitive 
functioning (Donohoe \& Benton, 1999).

Until recently, the existing research has assessed the effects of glucose levels in participants who have chronically low levels of glucose in their systems (e.g., hypoglycemic or diabetic patients; e.g., Lustman, Frank, \& McGill, 1991; Wredling, Theorell, Roll, Lins, \& Adamson, 1992). The findings suggest that extremely low levels of glucose are linked with ineffective emotion regulation (Benton \& Owens, 1993), increased impulsivity (Gailliot \& Baumeister, 2007), inability to suppress stereotyping (Gailliot, Plant, Butz, \& Baumeister, 2008), and binge eating and/or drinking (Baumeister, 2002; Baumeister, Vohs, \& Tice, 2007). As well, chronically low levels of glucose have been correlated with increased aggressive or criminal behaviours (Benton \& Owens, 1993). It is interesting to note that ego depletion research has also found that after performing a self-regulatory task, individuals are more likely to show increased aggression (DeWall, Baumeister, Stillman, \& Gailliot, 2007), demonstrate lesser ability to regulate their emotions (Eisenberg, Spinrad, \& Morris, 2002), and display increased levels of impulsivity (Heatherton \& Baumeister, 1996).

There are additional connections between the glucose findings and ego depletion findings, making it seem plausible that glucose is a contributor to self-regulatory performance. Ego depletion negatively affects performance on cognitively-demanding tasks, and recent studies have also shown that individuals perform worse on cognitivelydemanding tasks when their glucose levels are low (Gailliot, Baumeister, DeWall, Maner, Plant, Tice, Brewer, \& Schmeichel, 2007). Conversely, automatic cognitive tasks are relatively unaffected by level of glucose and level of ego depletion (Gailliot, Baumeister, DeWall, Maner, Plant, Tice, Brewer, \& Schmeichel, 2007). For example, both ego 
depletion and lowered glucose levels have been linked with impaired performance on incongruent trials of Stroop task (i.e., the word blue written in red ink), but not the congruent trials (Gailliot, et al., 2007; Owens, Parker, \& Benton, 1997). Also, recent studies have shown that after performing a self-regulatory task, glucose levels exhibit a significant decline (Gailliot, et al., 2007; Gailliot \& Baumeister, 2007). All of this suggests that self-control, or self-regulation, is reliant on a limited energy source that might be partially comprised of glucose. Perhaps the strongest evidence, however, comes from recent ego depletion studies that have successfully used glucose to measure cognitive fatigue (e.g., Gailliot, et al., 2007; Gailliot \& Baumeister, 2007). This has allowed for the manipulation of glucose levels as well as depletion levels.

With the understanding that glucose is linked to self-regulatory performance, studies have investigated the effects of ingesting glucose when in a state of cognitive fatigue (Benton, 1990; Markus, 2007). Increased glucose has now been linked to increased self-regulatory control on a number of cognitively-challenging tasks, such as Stroop task (Benton, et al., 1994; Donohoe \& Benton, 1999; Fairclough \& Houston, 2004) and mental arithmetic tasks (Kennedy \& Scholey, 2000). As well, increased glucose has been shown to lead to improved attentional control (Benton, Brett, \& Brain, 1987; Gailliot, et al., 2007), greater driving performance (Scholey, Harper, \& Kennedy, 2001), faster reaction times (Scholey, Harper, \& Kennedy, 2001; Scholey \& Kennedy, 2004; Kennedy \& Scholey, 2004), and increased helping behaviour (Gailliot, et al., 2007). The present study examines how ego depletion and glucose relate to behaving counter dispositionally.

Self regulation and acting counter dispositionally. There is evidence to suggest that 
acting out of character is ego depleting. In eight studies, Vohs, et al. (2005) examined the cognitive effects of acting counter to one's natural tendencies when presenting oneself in a social situation. In one of their studies, participants had to override their natural patterns of interaction by presenting themselves as modest to a stranger or as boastful to a friend. When participants had to present themselves in a new or unfamiliar way, they were more likely to show signs of ego depletion than when presenting themselves in a habitual manner. The results suggest that acting counter to one's natural tendency induces a state of cognitive fatigue, as measured by subsequent performance on cognitively-challenging tasks. This line of research shares similarities with Little's Free Trait Model of personality, which suggests that acting against one's own biogenic disposition leads to impaired psychological and cognitive functioning.

Little's (2000) Free trait Model and the studies conducted by Vohs, et al. (2005) suggest similar consequences. That is, both acting out of character and behaving counter to one's biogenic disposition seem to lead to cognitive-based costs. Together, these provide motivation for the main question of the proposed study. Are there costs associated with acting extraverted for dispositional introverts? This behaviour requires self-regulation to override a natural tendency and also requires behaviour that counters one's biogenic disposition. An answer to this question is likely to be that introverts who regulate their behaviour to be more extraverted experience a state of cognitive fatigue as a result. This may help explain why introverts are not more inclined to act extraverted, even though they experience increased positive affect.

Taking these proposals, Santoro (2007) conducted an initial test of the hypothesis that acting counter to one's personality disposition (i.e., in terms of extraversion) induces 
a state of cognitive fatigue. The study expanded the work of McNiel \& Fleeson (2006), who explored the relationship between state extraversion and positive affect by instructing participants to behave in either an extraverted or introverted manner during group discussions. Santoro (2007) replicated McNiel and Fleeson's (2006) study with the addition of a measure of ego depletion, in the form of the Stroop task. The results revealed that participants who acted extraverted experienced more positive affect than those who acted introverted, regardless of their disposition. Following the group discussion, the participants who were instructed to behave counter to their personality disposition made more errors on the trials on the Stroop task compared to those in behaviourally-concordant conditions. The findings were marginally significant and suggest that acting counter dispositionally in the domain of extraversion induces a state of cognitive fatigue. This study provided initial evidence that there are potential cognitive costs associated with acting in a counter-dispositional manner, even if acting extraverted is associated with increased positive affect.

\section{Present Study}

The present study was designed to further examine the hypothesis that acting counter dispositionally is ego depleting. Specifically, the aim of the study was to determine if people who score low on trait extraversion are cognitively fatigued after behaving in an extraverted manner. As well, it was designed to assess if the same pattern exists for extraverts acting introverted.

It is important to note that positive affect has been shown to lead to improved selfregulatory performance following exertion of cognitive energy on a previous task (Baumeister, Vohs, \& Tice, 2007). Positive affect does not seem to fully replenish 
cognitive resources, but instead improves it relative to individuals currently in a state of cognitive fatigue (Baumeister, 2002). Although positive affect appears to have a partly restorative effect, it has been suggested that positive affect may just motivate individuals to use more of their cognitive resources and further deplete the limited store (Baumeister, Vohs, \& Tice, 2007). The fact that positive affect seems to improve self-regulatory performance may explain why Santoro's (2007) findings were marginally significant. That is, the induced state of positive affect may have masked signs of cognitive fatigue. Therefore, in order to comprehensively assess cognitive fatigue, the present study used both performance and physiological measures. Specifically, cognitive fatigue was measured using both the Stroop task and blood glucose levels. If positive affect promotes the continued use of a depleted resource and not replenishment of cognitive energy, and if glucose is an underlying mechanism for self-control ability, then this should at minimum be reflected in lower serum glucose levels following the interview. Even if positive affect leads to some improvements in subsequent performance, there is no evidence to suggest that it leads to increases in glucose, which is known to be necessary for cognitive functioning. Therefore, it was put forward in the present study that blood glucose levels should show decrements after acting counter dispositionally. It has been argued that assessment of glucose may provide a more sensitive measure of cognitive fatigue, as well as provide diverse means of determining if acting counter dispositionally is ego depleting.

In the study, each participant engaged in an interview session with a confederate, during which he or she was instructed to behave in either an extraverted, introverted, or natural manner, according to a randomly-assigned condition. After acting in accordance 
with the behavioural condition, the participant's level of positive affect was assessed. Both at the start of the study and following the interview, the participant's blood glucose levels were measured to determine if there was a decrease in glucose associated with acting in a counter-dispositional manner. Each participant also completed a cognitively challenging task in the form of the Stroop task. Past research has shown that after performing a self-regulatory act, individuals either make more errors or take more time to complete the task than individuals who have not regulated their behaviour (e.g., Gailliot et al., 2007; Santoro, 2007). These procedures allowed for the examination of the ego depletion within the present study.

Consistent with past findings, the first hypothesis is that participants in the extraverted behavioural condition would report higher positive affect than those in the introverted condition, regardless of underlying personality disposition. As well, exploratory analyses were conducted to determine if there was a significant change in level of negative affect for dispositional introverts acting extraverted. Based on past findings, participants' levels of negative affect were not expected to differ significantly between behavioural conditions or personality dispositions. In addition, the second hypothesis is that extraverts in the introverted behavioural condition, and introverts in the extraverted condition, would show signs of cognitive fatigue after the interview.

Consistent with Santoro (2007), depleted participants were expected to make more mistakes on the Stroop task than non-depleted participants. The second hypothesis also predicts that depleted participants would show a greater decrease in glucose compared to participants in the behaviourally concordant conditions and the control condition. These hypotheses were tested within a 2 (introverted disposition vs. extraverted disposition) $\mathrm{x} 3$ 
(extraverted condition vs. introverted condition vs. neutral condition) ANOVA design.

As mentioned previously, people's actions, thoughts, and feelings are not stagnant, but vary over time and across situations (Fleeson, 2004). The present study provides an examination of potential limitations of behaving in a counter-dispositional manner, and may help to explain why introverts do not act extraverted more often, even if it makes them happy.

\section{Methods}

\section{Participants}

Participants consisted of 129 undergraduate psychology students, enrolled in either a first-year or second-year psychology course (i.e., PSYC 1001/1002 or 2001/2002). In return for their participation, they either received a one and a half percent increase to their final grade of the course or a ten-dollar incentive. Each participant also received the chance to win $\$ 200$ in a draw. Fifteen participants were removed from analysis because they did not follow the instructions to refrain from eating or drinking for three hours prior to participation, bringing the original total of 129 participants to 114 .

Mass testing was conducted at the beginning of the school year to obtain level of trait extraversion and contact information. In order to create groups of introverts and extraverts, only individuals with extraversion scores in the top and bottom $30^{\text {th }}$ percentile of the distribution were invited to take part in the study. Calculation of the top and bottom $30^{\text {th }}$ percentile of mean extraversion scores resulted in participants being classified as introverted if they received a mean score of 3.88 or less $(n=60)$ and extraverted if they received a mean score of 4.88 or greater $(n=54)$. The vast majority of students on the finalized list received a telephone invitation to participate. For 
individuals who did not provide their phone numbers in mass testing or did not answer the phone calls, they received an email with a password to sign up for this study in the online sign-up system (see Appendix D). This study was entitled Personality Impressions and was described as a study about personality impressions, physiology, and cognition. Each experimental session was carried out with one participant at a time and took approximately seventy-five minutes to complete.

\section{Materials}

Demographics. Each participant completed a demographics questionnaire at the beginning of the study (see Appendix E). Alongside obtaining age and sex, the questionnaire required the participant to self report if he or she had been diagnosed with either diabetes or glucose intolerance. Individuals with either diabetes or glucose intolerance need to be identified and removed due abnormal blood glucose levels. As well, the participant reported whether or not he or she had eaten anything within three hours prior to the study. This is necessary to determine because blood glucose levels fluctuate as a result of ingesting food and beverages.

Personality traits. During mass testing, participants' level of trait extraversion was measured using a subset of Goldberg's Mini Markers, which assesses trait extraversion and neuroticism (Saucier, 1994; see Appendix A). This 16-item questionnaire requires participants to rate how accurately various adjectives describe their typical behaviour on a seven-point Likert-type scale. Eight of the items assessed trait extraversion, including adjectives such as Bold, Energetic, Extraverted, and Talkative. A rating of seven indicates that the adjective is highly descriptive of the individual's behaviour in general, whereas a rating of one indicates that the adjective is a weak descriptor. For trait 
extraversion, Goldberg's Mini-Markers have a Cronbach's alpha of .81 and the coefficient for Goldberg's full-version personality scale ranges from .84 to .90 (Saucier, 1994). This scale was chosen because the adjectives all have high loadings on extraversion (McNiel \& Fleeson, 2006).

Interview. A 20-minute get-to-know-you interview was staged to provide a chance for enactment of state extraversion and introversion. A female confederate, blind to the purpose of the study, conducted the interview and was instructed to ask the participant a number of questions designed to give her an impression of the participant's personality. Some examples of questions were, What do you like to do on the weekends? If you could have any job, what would it be and why? (see Appendix I). Prior to the interview, the participant was given written and verbal instructions of how to behave in his or her randomly-assigned behavioural condition. Participants in the Acting Extraverted condition were instructed to emphasize parts of their personality that were bold, talkative, energetic, active, assertive, and adventurous both in their answers of the interview questions and in the way they presented themselves during the interview. Those placed in the Acting Introverted condition were told to act reserved, quiet, lethargic, passive, compliant, and unadventurous. Each of the adjectives provided in the behavioural instructions has high positive or negative loading on Goldberg's (1992) measure of extraversion. These instructions were used in McNiel and Fleeson's (2006) study; however, the two-person interview scenario was novel to the present study. There was also a control condition, where instruction was to act as naturally as possible. Overall, participants spent an average of approximately 17 minutes partaking in the interview with the confederate $(M=16.58, S D=3.96, \min .=8.13, \max .=24.40)$. 
Personality states. Each participant completed a questionnaire with 24 descriptive adjectives, eleven of which were used to determine his or her level of state extraversion (see Appendix K). Participants rated the extent to which each adjective described their behaviour during the interview. For example, adjectives such as, Energetic, Assertive, and Talkative were used as measures of extraversion. Adjectives such as Shy, Quiet, and Withdrawn were used as reverse-score measures. Participants rated each adjective on a seven-point Likert-type scale. In addition, the interviewer/confederate completed a 48adjective questionnaire assessing each participant's behaviour, which is derived from Goldberg's mini-markers personality scale (Goldberg, 1992; see Appendix N). The confederate rated the extent to which each adjective described the behaviour of the participant during the interview session. This extraversion scale has high internal consistency, as revealed by the Cronbach's alpha coefficient of .89. As an added security, the interview was videotaped. This was meant to allow for an independent viewer, who does not know the premise of the study, to be able to rate the participant's behaviour if there was any discrepancy between the self reports and the confederate reports. Combined, these questionnaires were obtained to ascertain that individuals behaved in accordance with their instructions.

Positive affect, Negative Affect, and Enjoyment. A questionnaire containing the Positive and Negative Affect Schedule (PANAS; Watson, Clark, \& Tellegen, 1988) was used to measure the participants' levels of positive and negative affect during the interview (see Appendix J). The participants were instructed to rate how they felt during the interview session. This scale consists of 28 adjectives that describe various emotions. The participants indicated to what extent each adjective represented how they felt during 
the interview on a seven-point likert-type scale. The confederate also completed this questionnaire (see Appendix M). The confederate was instructed to rate how she perceived the participant to have felt during the interview session. The positive affect scale $($ alpha $=.85)$ was comprised of five adjectives, such as interested, active, and strong. The negative affect scale $($ alpha $=.70)$ was made up of seven adjectives, such as irritable, upset, stressed, and nervous. In addition to this questionnaire, another questionnaire was added to determine if participants enjoyed the interview session. Each participant completed a questionnaire rating the extent to which he or she found the experience to be enjoyable (see Appendix L). The enjoyment scale (alpha $=.81)$ was composed of three statements, which were rated on a seven-point Likert-type scale (i.e., The interview was enjoyable, I had moments of fun during the interview, and, Frankly, I was bored throughout the entire interview).

Ego depletion. There are two measures of ego depletion that were used in this study. The first is a performance measure of ego depletion and the second is a physiological measure.

Stroop Task. A computerized Stroop task was adapted for the present study to measure ego depletion. The keyboard was set up with colour-coded keys to match the colour words that were presented on the screen. The task itself was divided into two parts. In the first part, participants were presented with coloured circles, to which they responded by pressing the matching colour on the keyboard. This section of the task was used to identify colour-blind individuals. In the second part of the task, participants were presented with colour words (e.g., blue, green, yellow). In the congruent trials, both the written word and the colour of the ink matched (e.g., the word blue written in blue ink). 
On the incongruent trials, the colour of the ink did not match the colour word written. For example, the word blue may have been written with green ink. For each of the trials, the participants were required to press the colour key that matched the colour of the ink, rather than the written word. There were a total of 276 trials on the Stroop task (i.e., 239 incongruent trials and 37 congruent trials). The accuracy of the participants' responses and mean response times were collected. It is important to note that mean response time was used instead of an overall sum and a percent error measure was used in place of a total error count due to the removal of trials for some participants and not for others. Specifically, trials in which the participant took less than $300 \mathrm{~ms}$ or longer than $3 \mathrm{~s}$ to respond were removed.

Glucose. Upon arrival and following the interview session, participants' levels of blood glucose were collected with a blood glucose meter. The device extracts a small amount of blood from the tip of the finger and is a commonly used measure of glucose in diabetic populations. Sterilizing pads, disposable lancets, and disposable test strips allowed for the safe testing of multiple participants. This process is virtually pain-free. The microelectric method of assessing change in glucose level following acts of self regulation has been used in previous studies as a measure of cognitive fatigue and has been shown to be reliable (Benton, Owens, \& Parker, 1994; Donohoe \& Benton, 2000; Gailliot, et al., 2007; Matthews, Holman, Bown, Steenson, Watson, Hughes, \& Scott, 1987; Meikle, Riby, \& Stollery, 2004).

\section{Procedure}

Students who completed mass testing, and were identified as introverts or extraverts, were either telephoned and signed up or emailed and given access to register 
for the study via an online sign-up system. Before registering to participate, individuals were told that participation in this study required them to refrain from eating and drinking for three hours prior to arrival. This was necessary to ensure accurate reading of the blood glucose levels (Gailliot, et al., 2007).

Upon arrival, the participant completed an informed consent sheet (see Appendix B) and a demographics questionnaire (see Appendix E). Next, he or she was randomly assigned to one of three conditions (i.e., extraverted, introverted, or control). Based on assigned condition, the participant received written and verbal instructions of how to behave during an upcoming interview session (see Appendices $\mathrm{F}$ to $\mathrm{H}$ ). Next, the participant's baseline level of blood glucose was assessed using a blood glucose meter, which measured glucose concentration in the blood stream (i.e., mmol/L). For this procedure, the fingertip was sterilized, and disposable lancets and test strips were used to collect the sample. This process took approximately 2 to 5 minutes to complete. A confederate, who was blind to the hypotheses of the study, was introduced as another participant who was instructed to conduct the interview (i.e., act as interviewer). The confederate's primary instructions were to ask a series of questions to the participant and maintain conversation for a 20 -minute period. There were a total of 3 confederates, of the same gender, that were used throughout the duration of this study, in order to maintain consistency across interviews. The interview session was used to provide participants with questions that allowed them to respond in a way so as to portray themselves as either extraverted or introverted (see Appendix I). The 20-minute session was videotaped. The interview time of 20-minutes was chosen in order to maximize the amount of time participants spent in their behavioural conditions. 
Following the interview, the participant was asked to complete a questionnaire package, containing the measures of positive and negative affect, the measure of state extraversion, and a survey of his or her opinion of the interview (i.e., enjoyment scale). The first questionnaire allowed for the examination of the hypothesis that acting extraverted, regardless of personality disposition, causes increased positive affect (see Appendix J). The second questionnaire was used to determine if the participants acted in accordance with their behavioural conditions (see Appendix K). The final survey was employed to determine the extent to which the participants enjoyed the interview (see Appendix L). At that time, the confederate also completed a questionnaire package assessing her impressions of the target participant. The confederate rated how she thought the participant felt and behaved during the interview (see appendices $\mathrm{M}$ and $\mathrm{N}$ ). This questionnaire was later used to determine if there was consistency between the confederate's ratings of the participant's behaviours and the participant's self-ratings of his or her behaviour. The participant's questionnaire package took approximately ten to fifteen minutes to complete.

Next, the participant's level of blood glucose was measured again. After this measure, the participant completed the Stroop Task. He or she was instructed to complete each trial as quickly and as accurately as possible. Both the measurement of glucose and the Stroop task performance were used for the examination of the hypothesis that acting counter to one's disposition is cognitively fatiguing. After completion of the study, the participant received both verbal and written form of debriefing (see Appendix C). 


\section{Results}

\section{Manipulation Check}

Before ascertaining that participants were acting in accordance with their behavioural instructions, correlational analyses were conducted to determine if a participant's self-reported extraverted behaviour matched the confederate's rating of his or her behaviour. The results revealed a high correlation between the ratings $(r=.73, \mathrm{p}$ $<.001)$. Since there was high correspondence between the confederate-reported and selfreported data, aggregated behaviour ratings were used in further analyses (see Table 1 for descriptive statistics). Correlational analyses were performed for all of the dependent measures and these descriptive statistics are located in Table 2. Only the Enjoyment scale was found to correlate significantly with other dependent measures. Specifically, the correlational analyses revealed that this scale is positively correlated with the positive affect scale $(r=.35, p<.01)$, and negatively correlated with the negative affect scale ( $r=$ $-.49, p<.01)$.

A One-way ANOVA of aggregated behaviour ratings was conducted to determine if the participants in each behavioural condition differed significantly in their level of enacted state extraversion. The results of the ANOVA revealed a significant main effect of condition on extraverted behaviour, $F(2,111)=60.66, p<.01$. LSD post hoc test revealed that each condition differed significantly from one another. Specifically, participants in the extraverted condition acted the most extraverted $(M=5.20, S D=.82)$, followed by the control condition $(M=4.66, S D=.82)$, and the introverted condition ( $M$ $=3.34, S D=.65)($ see Figure 1). 
Table 1

Ratings of mean extraverted behaviour and standard deviations across condition for each rater

$\begin{array}{lll}\text { Rater } & \text { M } & \text { SD }\end{array}$

Participant

Extraverted Condition

Introverted Condition

2.66

.87

Control Condition

4.54

1.23

Confederate

Extraverted Condition

5.21

.74

Introverted Condition

4.02

.70

Control Condition

4.78

.62

Aggregated rating

Extraverted Condition

5.20

.82

Introverted Condition

3.33

.65

Control Condition

4.66

.82

Note. The difference between each of the behavioural conditions was statistically significant for regardless of rater (i.e., self-report, confederate, aggregate). 


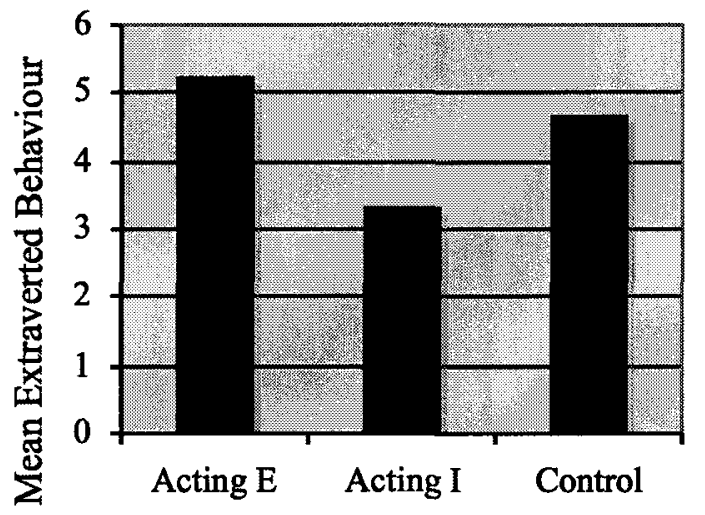

Figure 1. Mean extraverted behaviour as a function of behavioural condition (i.e., acting extraverted condition, acting introverted condition, and control condition).

Table 2

Intercorrelations between the dependent measures

\begin{tabular}{|c|c|c|c|c|c|c|}
\hline Measures & 1 & 2 & 3 & 4 & 5 & 6 \\
\hline 1. Positive affect & - & .09 & $.35^{* *}$ & .12 & .14 & -.01 \\
\hline 2. Negative affect & & - & $-.49 * *$ & .06 & .02 & .02 \\
\hline 3. Enjoyment & & & - & -.06 & .03 & .01 \\
\hline 4. Stroop errors & & & & - & .04 & .04 \\
\hline 5. Stroop reaction time & & & & & - & -.06 \\
\hline 6. Glucose change & & & & & & - \\
\hline
\end{tabular}

$* * p<.01$ 
The Stroop task was adapted for this study using the same basic design as in previous studies. In order to ascertain that the version designed for use in the present study is a satisfactory replication of the original task, participants should have had longer response times on the incongruent trials than the congruent trials. A paired-samples $t$-test revealed that, on average, participants took significantly longer to respond to incongruent trials $(M=825.26, S D=116.81)$ than congruent trials $(M=781.30, S D=107.97), t(113)$ $=-10.01, p<.01$. That is, when the written word and the colour of the ink did not match, participants took longer to respond than when the word was written in matching-coloured ink.

\section{Hypothesis 1: State Extraversion and Positive Affect}

The preliminary hypothesis of the present study was that, regardless of personality disposition, acting extraverted would be related to increased positive affect. A 2 (introverted disposition vs. extraverted disposition) x 3 (extraverted condition vs. introverted condition vs. neutral condition) ANOVA was conducted to assess differences in positive affect ${ }^{2}$. Based on McNiel and Fleeson's (2006) findings, I expected that acting extraverted would be related to higher positive affect than acting introverted, regardless of introversion-extraversion disposition. The results of the analysis conformed to expectations, in that personality disposition did not play a role in predicting level of positive affect, $F(1,108)=1.50, n s$. As well, there was no interaction effect between disposition and condition on level of positive affect, $F(2,108)=1.50, n s$. Lastly, there

\footnotetext{
${ }^{2}$ Note. Assumptions of Normality and Homogeneity of Variance (HOV) were violated for the analysis. Given the violation, a logarithmic transformation was conducted and yielded similar results. The nontransformed variable was used in the final analysis since the ANOVA generally robust despite theses violations. Specifically, the test is robust because I used a more stringent alpha to compensate for the HOV violation. Also, the ANOVA is relatively robust to the violation of normality because there are no outliers and dferror is over 20.
} 
was a significant main effect of behavioural condition on positive affect, $F(2,108)=$ $4.01, p=.02$, Partial $\eta^{2}=.07$. Post hoc analysis (LSD) revealed that individuals instructed to act extraverted reported significantly higher levels of positive affect $(M=4.11, S D=$ $.57)$ than individuals instructed to act introverted $(M=3.62, S D=.75)$ and individuals instructed to act naturally $(M=3.73 S D=.91)$. As well, individuals instructed to act naturally did not experience significantly higher levels of positive affect than those in the introverted condition (see Figure 2). 


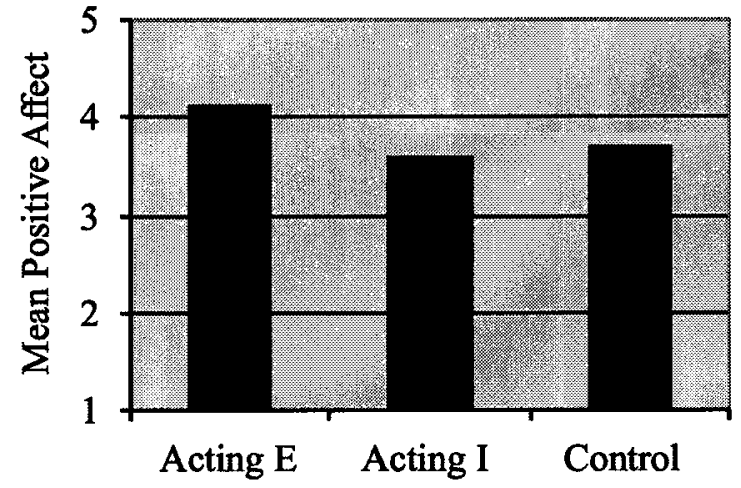

Figure 2. Distribution of mean positive affect scores by behavioural condition. 
A $2 \times 3$ ANOVA $^{3}$ was also conducted to determine if behavioural condition had an effect on enjoyment of the interview. As expected, there was no main effect of introversion-extraversion disposition on level of enjoyment during the interview, $F$ $(1,108)=2.64, n s$. As well, there was no significant interaction effect between disposition and condition on enjoyment, $F(2,108)=.09, n s$. Similar to the above positive affect findings, there was a significant main effect of condition on enjoyment of the interview, $F(2,108)=12.28, p<.01$, Partial $\eta^{2}=.19$. Post hoc analyses showed that individuals in the extraverted condition enjoyed the interview significantly more ( $M=$ $5.80, S D=1.17)$ than those in the introverted condition $(M=4.59, S D=1.30)$. Individuals in the introverted condition also enjoyed the interview significantly less than individuals in the control group $(M=5.52, S D=1.00)$; however, there was no significant difference found between the extraverted and control conditions, which differs from the result found on positive affect. That is, individuals instructed to act extraverted reported experiencing statistically similar levels of enjoyment during the interview.

With regards to negative affective experience, it could be argued that although introverted individuals experience increased positive affect while acting extraverted, they might also experience increased negative affect as well, because the behaviour is out of character. A correlational analysis revealed no significant correlation between positive and negative affect during the interview $(r=.09, p=.33)$. As well, during the interview, the participants experienced higher levels of positive affect than negative affect.

Another $2 \times 3$ ANOVA was conducted to assess any differences in negative affect that may have occurred as a result of the interview. Consistent with previous research,

\footnotetext{
${ }^{3}$ The assumption of Normality was violated for all of the ANOVAs conducted within this study. However, since dferror was over 20 and there were no outliers, the analyses were performed without transforming any of the dependent variables.
} 
negative affect did not differ significantly based introversion-extraversion disposition, $F$ $(1,108)=1.95, n s$. As well, there was no significant interaction effect on level of negative affect, $F(2,108)=.68, n s$. Conversely, there was a significant main effect of condition on level of negative affect, $F(2,108)=6.45, p<.01$, Partial $\eta^{2}=.11$. LSD post hoc analysis revealed that individuals in the Acting Introverted condition had significantly higher levels of negative affect $(M=2.82, S D=.91)$ than individuals in both the Acting Extraverted condition $(M=2.41, S D=.95)$ and the control condition $(M=2.09, S D=$ .81 , see Figure 3). There was no difference in level of negative affect between the extraverted and control conditions. This result is a replication of the finding in Santoro's (2007) study, which highlights the notion that individuals do not enjoy being told to behave in an introverted manner during a social interaction, regardless of underlying personality disposition. In sum, there was no evidence from the analyses that behaving in an extraverted manner leads to increased negative affect or self-reported stress for dispositional introverts. 


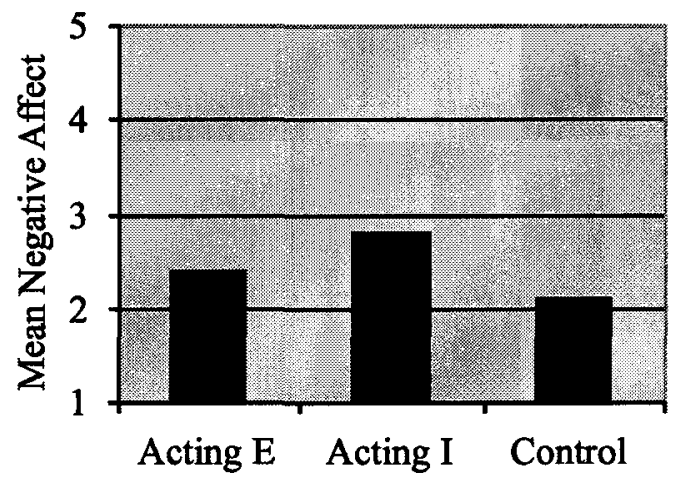

Figure 3. Mean negative affect scores as a function of behavioural condition. 
Hypothesis 2: Acting Counter-Dispositionally leads to Cognitive Fatigue.

I hypothesized that extraverts in the introverted condition, and introverts in the extraverted condition, would show signs of cognitive fatigue after the interview compared to participants in the control condition and those in conditions that were concordant with their dispositions. Cognitive fatigue was expected to be reflected in both poorer performances on the Stroop task, and in decreased glucose levels.

Stroop task. In order to test the hypothesis that acting out of character in terms of one's introversion-extraversion disposition leads to cognitive fatigue, two 2 X 3 ANOVAs were conducted on the number of errors made and mean reaction time. As expected, the first ANOVA revealed no main effect of personality disposition, $F(1,108)$ $=.44, n s$, nor of behavioural condition, $F(2,108)=.79, n s$, on number of errors made on the Stroop task. Inconsistent with the study's hypothesis, there was not a significant interaction effect on the mean number of errors made on the Stroop Task, $F(2,108)=.47$, $n s$ (see Table 3). 
Table 3

Mean Number of Errors Following Interview Session

\begin{tabular}{llll}
\hline Behavioural Condition & \multicolumn{1}{c}{ Disposition } & $\mathrm{M}$ & $\mathrm{SD}$ \\
\hline Acting Extraverted & Introvert & 1.58 & 1.22 \\
& Extravert & 2.08 & 1.40 \\
& Total & 1.75 & 1.23 \\
\hline Acting Introverted & Introvert & 1.48 & 1.38 \\
& Extravert & 1.55 & 0.99 \\
& Total & 1.51 & 1.17 \\
\hline Control & Introvert & 1.63 & 1.33 \\
& Extravert & 1.78 & 1.25 \\
& Total & 1.70 & 1.29 \\
\hline
\end{tabular}


With regards to reaction times, the results of the ANOVA showed no significant main effect of behavioural condition, $F(2,108)=.63$, $n s$, or of disposition, $F(1,108)=$ $.70, n s$ (see Table 4). The ANOVA revealed, however, a marginally significant interaction effect on mean reaction time, $F(2,108)=2.21, p=.12$, Partial $\eta^{2}=.04$. The results suggest that the participants who were required to act counter dispositionally took more time, on average, to respond on each trial than individuals who were in conditions that corresponded with their dispositions (see Figure 4). Table 4 outlines the descriptive statistics for the interaction effect on mean reaction times. It appears that there is a trend towards cognitive fatigue when acting counter dispositionally in the form of slower reaction time. 


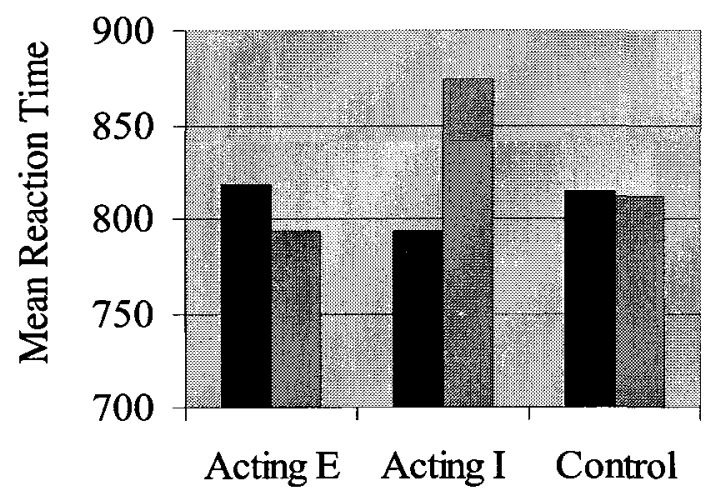

- Introverted $\quad$ Extraverted

Figure 4. Mean reaction times (ms) as a function of behavioural condition and personality disposition. 
Table 4

Mean Reaction Times (in milliseconds) Following the Interview

\begin{tabular}{lllcc}
\hline \multicolumn{1}{c}{ Condition } & Disposition & $\mathrm{N}$ & $\mathrm{M}$ & $\mathrm{SD}$ \\
\hline Acting Extraverted & Introverted & 27 & 817.59 & 101.44 \\
& Extraverted & 14 & 793.31 & 97.27 \\
& Total & 41 & 809.30 & 102.16 \\
\hline Acting Introverted & Introverted & 18 & 793.47 & 123.26 \\
& Extraverted & 20 & 874.36 & 143.15 \\
& Total & 38 & 836.04 & 138.48 \\
\hline Control & Introverted & 15 & 814.07 & 96.61 \\
& Extraverted & 20 & 812.03 & 99.95 \\
& Total & 35 & 813.03 & 99.95 \\
\hline & $\begin{array}{l}\text { Introverted } \\
\text { Total } \\
\text { Extraverted } \\
\text { Total }\end{array}$ & 60 & 809.47 & 107.72 \\
\hline
\end{tabular}


Glucose. A 2 X 3 ANOVA on change in glucose levels ${ }^{4}$ was conducted to determine if the participants' level of glucose differed significantly from before to after the interview and if an interaction effect exists. Specifically, I expected introverts in the extraverted condition, and extraverts in the introverted condition, to show a greater decrease in blood glucose level than individuals in either the control condition or in behavioural conditions that were concordant with their personality dispositions.

As predicted, the ANOVA revealed no main effect of condition on change in glucose, $F(2,108)=.40, n s$; nor was there a significant main effect of disposition on change in glucose levels, $F(1,108)=.04, n s$. In addition, results of the ANOVA showed no significant interaction effect on change in glucose, $F(2,108)=.94$, $n s$ (see Table 5). That is, contrary to predictions, participants who acted out of character did not show greater decline in their glucose levels compared to the other participants.

Interestingly, however, during the experiment, it seemed apparent that glucose levels generally increased from before to after the interview session, as opposed to decrease or remain the same. A paired-samples $t$-test revealed a significant increase in glucose from before $(M=4.95, S D=.51)$ to after $(M=5.10, S D=.63)$ the interview session for all participants, regardless of behavioural condition and disposition, $t(113)=$ $-2.97, p<.01$.

\footnotetext{
${ }^{4}$ Change in glucose was attained by calculating a difference score between the baseline and post-interview glucose levels.
} 
Table 5

Mean glucose levels before and after the interview

\begin{tabular}{llccc}
\hline \multicolumn{1}{c}{ Condition } & Disposition & $\begin{array}{c}\text { Baseline } \\
\text { glucose }\end{array}$ & $\begin{array}{c}\text { Post-interview } \\
\text { glucose }\end{array}$ & $\begin{array}{c}\text { Change in } \\
\text { glucose }\end{array}$ \\
\hline $\begin{array}{l}\text { Acting } \\
\text { Extraverted }\end{array}$ & Introverted & 5.02 & 5.17 & .16 \\
& Extraverted & 5.14 & 5.34 & .20 \\
& Total & 5.08 & 5.26 & .18 \\
\hline Acting Introverted & Introverted & 4.76 & 4.83 & .07 \\
& Extraverted & 4.89 & 5.17 & .28 \\
& Total & 4.83 & 5.00 & .18 \\
& Introverted & 4.97 & 5.11 & .15 \\
& Extraverted & 4.93 & 4.95 & .02 \\
\hline Control & Total & 4.95 & 5.04 & .08 \\
\hline & $\begin{array}{l}\text { Introverted } \\
\text { Total } \\
\text { Total }\end{array}$ & 4.91 & 5.04 & .13 \\
\hline
\end{tabular}




\section{Additional Analyses}

Time of day. Individuals were instructed to refrain from eating and drinking for three hours prior to participation in the study. However, participants who arrived in the morning most likely fasted throughout the entire night, whereas afternoon participants likely ate at least breakfast. In order to rule out the possibility that glucose levels fluctuated as a function of the time of day ${ }^{5}$ someone participated, One-way ANOVAs were conducted to see if there was a significant glucose difference between the participants who participated before noon and those who participated afterwards. The results revealed no pattern in change in glucose as a function of the time of day one participated, $F(1,112)=.08$, ns. Additionally, while post-interview levels of glucose were unaffected by time of day, $F(1,112)=1.73, n s$, there was a marginally significant main effect on baseline glucose levels, $F(1,112)=3.70, p=.06$, Partial $\eta^{2}=.03$. Across condition and disposition, glucose levels were higher in the afternoon $(M=5.04, S D=$ $.56)$ than in the morning $(M=4.86, S D=.45)$. This is not surprising, since a large portion of individuals who participated in the morning fasted overnight, whereas those in the afternoon often ate at least breakfast that morning. Though not statistically significant, post-interview glucose levels were also slightly higher in the afternoon $(M=5.17, S D=$ $.70)$ than in the morning $(M=5.02, S D=.55)$. In summary, individuals who participated in the afternoon had higher baseline glucose levels than those who arrived in the morning. Despite these differences, both the morning and afternoon participants showed the similar patterned increase in glucose following the interview (see Figure 5). A $2 \times 3$ (behavioural condition $\mathrm{x}$ disposition) ANCOVA was conducted on change in glucose,

\footnotetext{
${ }^{5}$ Time of day was calculated as a fixed variable with two levels (i.e., level 1: before 12:00 pm, level 2: $12: 00 \mathrm{pm}$ and later.
} 
using time of day as a covariate. The results showed that controlling for the effect of time of day did not lead to any significant main effects or interaction effects on change in glucose. It is reasonable to ascertain that time of day did not mask any effects of the experimental manipulation on changes in glucose level. 


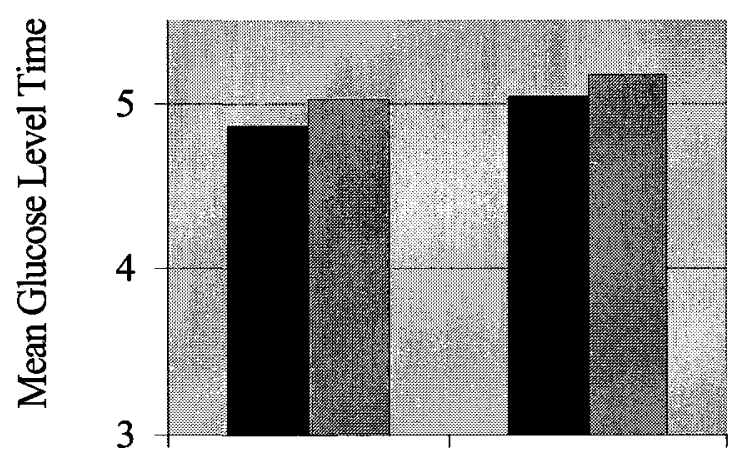

Baseline glucose Post glucose

Morning Afternoon

Figure 5. Mean glucose levels both before and after the interview session as a function of time of day. 
Gender effects. There was reason to suspect that gender may have had an effect on amount of cognitive energy expended during the interview session. Specifically, it could be reasoned that male participants may have had to regulate more extensively during the interview session than females. That is, this interview scenario is very similar to a firstdate interaction, where one partner asks a number of personal questions to the other in order to get to know him or her better. Having to balance a moderate level of selfdisclosure with a member of the opposite sex, while also following behavioural instructions, may be more taxing for male participants than the females. With this in mind, I conducted a series of analyses to assess whether or not gender was masking any experimental effects. First, a Chi-square analysis was conducted in order to see if there were gender differences in personality disposition. The results revealed that personality disposition did not differ based on gender, $\chi^{2}=.18, n s$. Next, One-way ANOVAs were conducted to examine if gender had a significant effect on the measures of ego depletion. There was a significant main effect of gender on both baseline glucose levels, $F(1,112)=$ $8.12, p=.01$, and post-interview glucose levels, $F(1,112)=13.34, p<.01$; however, gender alone did not account for the change in glucose from before to after the interview, $F(1,112)=2.17, n s$. Specifically, males $(M=5.14, \mathrm{SD}=.56)$ had higher baseline glucose than females $(M=4.86, S D=.47)$. As well, males $(M=5.39, S D=.59)$ had higher post-interview glucose than females $(M=4.95, S D=.60)$ ( see Figure 6). Lastly, an ANCOVA was conducted, controlling for the effect of gender on change in glucose. Controlling for gender did not lead to any significant interaction effects or main effects on change in glucose. It is reasonable to state that gender was not masking any effects of the experimental manipulation on glucose levels. 
With regards to Stroop performance, a one-way ANOVA revealed a marginally significant main effect of gender on number of errors made, $F(1,112)=2.95, p=.09$. Specifically, male participants $(M=2.00, \mathrm{SD}=1.51)$ made more errors than female participants $(M=1.56, S D=1.16)$. This is consistent with the notion that males were using more regulatory resources during the interview. In order to ascertain that gender alone was not masking any effects of the experimental manipulation, an ANCOVA was conducted. The results showed that, when gender is controlled, there is still not a significant interaction effect between behavioural condition and disposition on number of errors made on the Stroop task, $F(2,107)=.40, n s$.

With reference to Stroop reaction times, a one-way ANOVA revealed no main effect of gender on reaction time, $F(1,112)=.10, n s$. In order to ascertain that gender did not obscure any effects of depletion, an ANCOVA was conducted on mean reaction times. Controlling for gender did not change the level of significance of the interaction effect between condition and disposition on mean reaction time found in the original $2 \times 3$ ANOVA, $F(2,107)=2.20, p=.12$. Overall, it is reasonable to state that gender did not mask any effects of depletion that may have resulted from the experimental manipulation. 


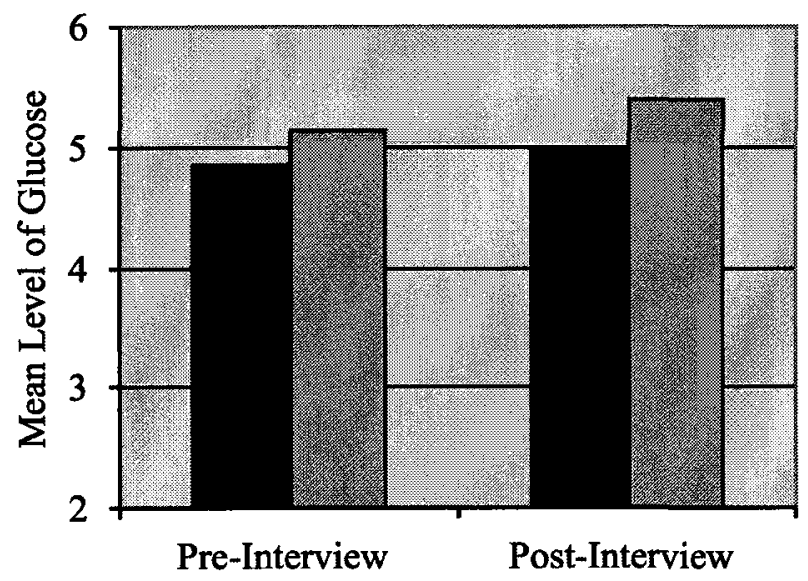

Female Male

Figure 6. Mean glucose levels before and after the interview across gender. 


\section{Discussion}

The present study is an investigation of a potential cost associated with acting counter-dispositionally. The study's primary goal was to extend the past research finding that acting counter dispositionally is cognitively fatiguing (Santoro, 2007). That is, although both introverts and extraverts may receive an increase in positive affect when acting extraverted, introverts may have to regulate their behaviour in order to receive the benefit. The act of regulation may be a cost inherent in acting extraverted for introverts, since it can lead to a state of cognitive fatigue. Within the present study, I hypothesized that acting counter to one's introversion-extraversion disposition would be related to cognitive fatigue, as shown in decreased performance on the Stroop task and decreased glucose levels.

With regards to the main hypothesis of this study, the research findings were mixed. Across both the behavioural and physiological measures, there was not a clear and precise pattern of ego depletion after acting counter dispositionally. The present study revealed the trend that participants who were instructed to act counter dispositionally showed signs of cognitive fatigue in the form of slower mean reaction times compared to participants who acted consistently with their disposition. Although the interaction effect for mean reaction times was only marginally significant, this shows a trend that is in the predicted direction.

Stroop findings regarding cognitive fatigue have come in the form of either increased errors or slower reaction time (e.g., Ferrari, \& Pychyl, 2007; Santoro, 2007). That is, when depleted, individuals either need to take more time to maintain accuracy or make more errors in attempting to maintain speed. It is not surprising, then, that since 
there was a marginal effect on reaction time that there was no difference in number of errors made. However, unexpectedly, the findings regarding glucose were inconsistent with expectation, showing no interaction between disposition and behavioural condition on change in glucose. In fact, the results showed a general increase across participants, with no interaction between personality trait and state behaviour.

Several things might explain the variability of the results. First, there is the possibility that the experimental manipulation was not sufficiently depleting to show a clear effect. Relating to the interview, the addition of self-disclosure within the discussion may have been a limiting factor. Even though participants were provided with behavioural instructions, they were also told not to lie about themselves during the get-toknow-you interview. As well, the confederates were instructed to maintain eye contact with the participant, nod and give affirmation to him or her, as well as try to get the participant to elaborate on information given. Past research has demonstrated that engaging in conversation with an accepting partner leads to increased positive affect (Augustine \& Hemenover, 2008) and decreased use of regulatory energy (DeWall et al., 2008).

One explanation for this relationship comes form the Satiation hypothesis, which states that interacting with an accepting peer satisfies an underlying need to belong that drives self-regulatory behaviour. This need is not necessarily conscious, but rather is underlying regulatory behaviours. Therefore, when this need has been satisfied temporarily, such as in a conversation with an accepting and non-judgmental person, motivation to self-regulate decreases and one uses less regulatory energy (Baumeister, Gailliot, DeWall, and Oaten, 2006; DeWall et al., 2008; Ryan \& Deci, 2008). Past 
studies have shown that after being accepted, individuals exert less regulatory energy on a cognitive task than individuals in a control condition (DeWall et al, 2008). In the present study, participants spent an average of 16 minutes disclosing personal information about themselves to a partner that appeared non-judgmental and accepting. Although the satiation hypothesis is only one possible explanation for the findings, it seems that there is a relationship between feeling accepted and of self-regulatory exertion.

In addition, the results pertaining to cognitive fatigue may have been weak because the experimental manipulation was not strong enough to induce the level of cognitive fatigue necessary for individuals to start conserving cognitive energy. The two-person paradigm in the present study may not have required as much regulatory energy as the three-person paradigm used in Santoro's (2007) study, where participants' levels of extraverted and introverted behaviours were more noticeable and extreme. In this twoperson interaction, the mean difference in level of extraverted behaviour across condition was not as large as the 3-person scenario. Supporting this notion, past research has found that the larger the group size, the more noticeable the differences in extraverted or introverted behaviour become (Kuk, 2000).

Alternatively, the lack of a clearly-defined relationship between acting counter dispositionally and cognitive fatigue may be due a missing element in the equation. That is, perhaps regulation becomes more apparent in situations where it is less socially acceptable to act either introverted or extraverted and not the other. If the situational expectations go against the individual's natural tendency and comfort zone, the individual may feel pressure to regulate his or her behaviour more in order to conform. 
This notion has been tested by Vohs et al (2005). Our studies are similar in that both used two-person discussions; however, Vohs et al (2005) had individuals act out of character in ways that were socially unacceptable (i.e., modest to a stranger and boastful to a friend). In the present study, it could be argued that it is not socially unacceptable to act either in an introverted or extraverted manner when talking to one other person. It is true that participants in the extraverted condition acted significantly more extraverted than those in the introverted conditions. As well, all participants were invited based on having introversion-extraversion disposition scores in the top and bottom $30^{\text {th }}$ percentiles. However, since it is socially acceptable to act in both manners, perhaps the situation itself is not depleting enough to see differences in later regulatory performance or in glucose.

In order to see an effect of depletion with regards to acting counter-dispositionally, the situation may need to be inherently more acceptable to act introverted but not extraverted, or vice versa. For example, at a social gathering, it is expected that you will socialize with others and act in a more extraverted manner. The individual who acts more introverted will stand out in this scenario. Since in this situation the one behaviour is more socially acceptable than the other, the introverted individual might feel compelled to regulate his or her behaviour to act more extraverted. In a situation like this, where acting in accordance with one's natural tendencies is less ideal, the individual may experience more motivation to regulate to the point of depletion. As well, the more introverted one is, the more he or she may need to regulate in a situation that is inherently extraverted. The situation chosen for this study may have not required sufficient regulatory energy to act far out of character.

Past research has suggested that inducing positive affect leads to further exertion of 
cognitive energy once depleted (Baumeister, 2002; Baumeister, Vohs, \& Tice, 2007). The present study's varied findings might have resulted from positive affect buffering the effects of ego depletion, by leading to increased use of regulatory energy on the Stroop task, following the interview. That is, positive affect may have led to more exertion of cognitive energy following the experimental manipulation, thereby improving Stroop performance for some individuals. All participants in the extraverted condition experienced higher levels of positive affect than those in the introverted condition. As well, the pattern of results, though not statistically significant, showed that introverted individuals in the extraverted condition performed better on the Stroop task than extraverts in the introverted condition. Specifically, introverted individuals who acted extraverted seemed to take less time to respond on each trial than the extraverted individuals in the introverted condition. The pattern of results indicates that they did not perform as well as individuals who were in conditions that matched their dispositions, but they performed better relative to the others who acted counter-dispositionally, but who did not receive the boost of positive affect. The correlational analyses of the dependent measures, however, did not show a significant relationship between positive affect and Stroop performance.

Although it has been suggested that positive affect may buffer the effects of selfregulatory fatigue, there is no evidence that positive affect has a direct effect on level of blood glucose. This is one reason that glucose was used as second measure of depletion. However, the findings regarding glucose showed no interaction effect and no differences in glucose based on level of positive affect experienced. The results regarding glucose pose unique issues that need to be addressed separately. In the present study, blood 
glucose levels did not conform to expectations by decreasing as a function of acting counter dispositionally. Aside from the present study, there is some evidence to suggest that blood glucose level alone may not be a sufficient indicator of self- regulatory ability and cognitive performance. Although some studies have shown that blood glucose levels decrease following cognitive performance or that glucose administration improves cognitive performance, there are also a number of studies that do not show this effect (e.g., Allen, Gross, Aloia, \& Billingsley, 1996; Benton et al., 1990; Green, Elliman, \& Rogers, 1997; O'Hanlon \& Horvath, 1973; Meikle et al., 2004; Scholey \& Kennedy, 2004). In effect, the dynamics of the relationship between blood glucose and cognitive functioning are not fully understood (Meikle et al., 2004; Scholey et al., 2001).

It is clear, though, that there are a number of internal and external factors that influence the fluctuation of levels of serum glucose (Benton, 2002; Green et al., 1997; Meikle et al., 2004; Scholey et al., 2001). Internally, there are a number of counterregulatory hormones that exert substantial influence on the rise and fall in blood glucose levels, such as adrenaline and cortisol (Donohoe \& Benton, 1999; Fibiger, Evans, \& Singer, 1986). Under demanding circumstances, these hormones are known to trigger the release of glucose into the blood stream (Benton et al, 1990). For example, when glucose levels become low, this reduction stimulates the production and release of adrenaline and noradrenaline. After some delay, this release triggers a series of events, one of which is the mobilization of free fatty acids, which in turn sends a signal to the liver to release further amounts of glucose into the blood stream (O'Hanlon \& Horvath, 1973). As well, other factors, such as heart rate acceleration, are suspected to play a role in the relationship between glucose and cognitive performance (Green, et al., 1997; Kennedy \& 
Scholey, 2000; Owens et al, 1997; Scholey et al, 2001). Combined, this reveals some of the complexity of the internal system in which glucose is regulated. These factors may also help explain why blood glucose levels do not show circadian fluctuations throughout the day, even though self-regulatory ability does.

The relationship between glucose and self-regulation was proposed after conducting studies showing the relationship between momentary rise and fall in blood glucose and cognitive performance. Specifically, low glucose has been linked with weakened selfregulatory performance and glucose administration has been connected to improved cognitive performance (e.g., Benton et al., 1994; Gailliot et al., 2007). As well, selfregulation tasks have been shown to lead to decreases in glucose and later decrements to regulatory performance (Gailliot \& Baumeister, 2007; Gailliot et al, 2007). Conversely, there is some evidence indicating deficiencies in the relationship between blood glucose and self regulation. For instance, self-regulatory reserves replenish as a result of sleep; however, sleep has no patterned effect on blood glucose (Gailliot, 2008; Jarrett, 1979). Connected to this, self-regulation is more effective in the morning than it is in the evening, whereas blood glucose levels do not show patterned fluctuations throughout the day (Gailliot, 2008). Both physical and mental exercise improve self-regulatory performance over time, whereas glucose is largely unaffected by these activities (Gailliot, 2008). The inconsistencies in the relationship between blood glucose and self regulation have prompted the proposal of alternative glucose-related mechanisms to explain the physiological underpinnings of regulatory capacity, such as glycogen and glucose tolerance (Craft et al., 1994; Gailliot, 2008; Kennedy \& Scholey, 2000).

Upon arrival in the brain, a portion of glucose is converted and stored in the form of 
glycogen. When glucose levels start to deplete in the brain, it is believed that glycogen is further converted into lactate to be used directly by neurons in the brain (Gailliot, 2008; Magistretti, Pellerin, Rothman, \& Shulman, 1999). Comprising 1-6\% of the brain's energy source, glycogen is thought to be used in normal populations when performing tasks of executive functioning (Gailliot, 2008). In fact, Gailliot (2008) has proposed that this is a better indicator of self-regulation since it is directly related to the brain's energy consumption during cognitive performance.

Glucose tolerance has also been suggested as a physiological contributor to self regulation. That is, one's ability to regulate behaviour may be related to one's capacity to transport glucose effectively from the blood stream into the brain. There are a number of studies that have shown the relationship between glucose tolerance and complex cognitive task performance (e.g., Allen et al., 1996; Craft et al., 1994; Meikle et al., 2004). Specifically, good glucose tolerance (or glucose regulation) is linked with better cognitive performance than poor glucose tolerance. As well, one's ability to regulate glucose has the same daily circadian rhythm that self-regulation does (Gailliot, 2008; Gailliot \& Baumeister, 2007; Sunram-Lea, Foster, Durlach, \& Perez, 2001). Also, one's ability to regulate glucose fluctuates as a function of sleep, time of day, and exercise. Combined, these factors may influence cognitive functioning and performance.

In the present study, blood glucose level did not decrease as a result of acting counter dispositionally. However, there was a statistically significant increase of glucose for participants in the study, regardless of condition and disposition. This finding was largely unexpected; however, as outlined above, there are a number of internal and external factors that influence glucose levels in ways that we do not fully understand. For 
example, there is the possibility that the pin-prick method used to collect the blood glucose levels caused a cycle of internal events leading to increased glucose (Donohoe et al, 1999). It has been proposed that the finger-prick method leads to increased cortisol, which, through a series of internal changes, leads to a spike in glucose levels (Donohoe et al., 1999). However, a number of studies have found glucose decreases following tasks of self regulation using this means of measurement (e.g., Gailliot et al, 2007; Donohoe et al, 1999).

In summary, the present study uncovered some behavioural evidence of a trend towards ego depletion after acting counter dispositionally; however, the physiological measure did not provide conclusive support in the same direction. Since blood glucose is part of a complex process that is not fully understood, there is reason to view the marginally significant effect on Stroop performance as being suggestive of cognitive fatigue.

With regards to the hypotheses pertaining to positive affect, it seems clear that following instructions to act extraverted leads to higher positive affect than acting introverted during social interaction. The finding that extraverted behaviour was related to higher positive affect than introverted behaviour was anticipated, since this has been found in past studies (McNiel \& Fleeson, 2006; Santoro, 2007). However, unlike the present study, Santoro (2007) previously found that individuals instructed to act extraverted experienced the same level of positive affect as those in the control condition. This posed the question: Is it the social situation or the instructed extraverted behaviour that is most related to momentary fluctuations in positive affect? The findings in the present study do not lead to a conclusive answer to this question. Even though 
individuals in the control condition and in the extraverted condition had statistically different levels of positive affect, the actual difference in affective experience was rather small.

With regards to level of enjoyment (i.e., the survey of opinions of the interview ), individuals in the control condition experienced the same level of enjoyment as those instructed to act extraverted. So, being told to act extraverted and being told to act naturally seem similarly related to enjoyment. Overall, the present study adds support to the notion that being told to act extraverted leads to higher levels of positive affect than being told to act introverted. However, it is unclear whether the benefits of being told to act extraverted outweigh what is experienced when the individual acts naturally in a social setting.

When acting extraverted, it is plausible that an introvert might experience increased stress or negative affect, which might explain why they do not engage in the behaviour more often (McNiel \& Fleeson, 2006). Within the present study, participants in each behavioural condition experienced low levels of negative affect. When comparing groups, individuals in the introverted condition experienced the highest levels of negative affect. The low levels of negative affect and lack of interaction effect suggest that introverted individuals who were in the extraverted behavioural condition did not experience increased negative affect or self-reported stress during the interview. This does not imply that they do not experience a physiological increase in stress level, since physiological stress and subjective experience of stress do not always covary; however, this hypothesis was not tested within the scope of the present study. In summary, the pattern shows that acting extraverted is linked with higher positive affect and enjoyment 
than acting introverted in a social situation. As well, it seems that acting extraverted is linked with higher positive affect without increased negative affect. What remains to be determined is if the benefit of positive affect that introverts receive outweighs what they might experience by following instructions to act naturally in a social situation, especially if acting extraverted requires introverts to regulate their behaviour and leads to cognitive fatigue.

\section{Limitations}

There are a number of limitations that may have influenced the strength of the findings. One limitation linked to the interview is the wide variability in discussion times, which ranged from 8 to 24 minutes. Although the participant and the confederate were instructed to maintain conversation for 20 minutes, this was often not achieved. It is reasonable to expect that the amount of depletion that would be apparent after an 8minute conversation is quite a bit less than what would be expected after 24 minutes. Length of interview time was not correlated, however, with either glucose levels or Stroop performance. As well, ANCOVAs revealed that controlling for length of discussion produced no main effects or interaction effects on any of the dependent measures. Future studies should consider designing a scenario in which length of time is regulated.

Another potential limitation within the present study may be related to issues of measurement. Firstly, participants spent an average of 5 minutes completing questionnaires, from the time the interview finished to the final glucose measurement. This time increased to close to 10 minutes between the end of the interview and the start of the Stroop task. Past research has demonstrated that cognitive resources begin to 
replenish during periods of rest (Baumeister, 2002). With that said, the process of repletion is slower than that of depletion; therefore, one would still expect to see signs of depletion if the self-regulatory activity required enough exertion. However, it could be argued that completion of questionnaires does not constitute a period of rest and actually requires cognitive energy. Questionnaire completion was not timed during the present study, though future research might consider actually using the length of time taken to complete the questionnaires as another measure of depletion. Individuals who were more depleted may have taken longer to complete their questionnaire package. This would be consistent with the slower reaction times seen on the Stroop task.

There is also a potential limitation regarding the use of blood glucose as an indicator of cognitive fatigue. There are a number of studies that suggest that glucose intolerance or diabetes creates high levels of blood glucose that do not correspond to the amount of glucose in the brain that is being used for cognitive processing. In order to experimentally test for glucose intolerance or poor glucose tolerance, however, participants would have had to be administered glucose and monitored over time (Benton, 2002). This was not considered feasible within the scope of the present study due to the number of constraints already placed on recruitment, such as only being able to use participants who completed mass testing and obtained specific extraversion scores. As well, random assignment of participants into behavioural conditions should have addressed this concern, since there is no reason to suspect that glucose tolerance or diabetes is associated with introversion-extraverted disposition. In the present study, glucose intolerance and diabetes may not have created spurious effects, but could have contributed to the lack of significant findings. In order to identify some people who were 
glucose intolerant or diabetic, participants completed a questionnaire that asked if they had been diagnosed with either condition. Had someone identified himself or herself as having one of these conditions, the participant would have been removed from data analyses. However, no one self-reported having any of the conditions. With a number of studies showing a relationship between glucose tolerance (or gluco-regulatory ability) and cognitive performance, future research should either control for extreme cases (i.e., glucose intolerant or diabetic individuals) or should use gluco-regulatory ability as another measure of self-regulation and fatigue.

Another potential limitation may be the fact that the demographics questionnaire was missing an important question. The survey required participants to report if they had eaten anything within the three hours prior to arrival, and if so, what they ate. However, there was no question that asked participants if they had anything to drink before participation. When participants signed up for the study, they were instructed not to drink anything three hours prior to arrival at the laboratory; however, there was no written record regarding their beverage intake. Upon arrival, the researcher asked each participant if they had anything to eat or drink. As well, many participants offered this information on the questionnaire; however, it is reasonable to suspect that a number of participants did not. This limitation can impact the results of the experimental manipulation, because the intake of beverages with sugar content leads to increased glucose.

Lastly, another potential limitation may be overall sample size. After dividing participants into groups based on both their disposition and assigned behavioural condition, it became apparent that cell sizes were relatively small. A larger sample size 
would provide greater statistical power to the analyses, increasing the ability to show a potential interaction effect.

\section{Conclusions}

On the whole, this study offers an examination of the relationship between personality traits, personality states, affect, and cognitive fatigue. More specifically, the present study aimed to uncover costs that may be associated with acting out of character for introverts who are instructed to act extraverted. The present study predicted that individuals would experience higher positive emotions when acting extraverted compared to acting introverted. However, it was also expected that individuals would experience cognitive fatigue when acting in a counter-dispositional manner.

Past research supports the notion of a relationship between state extraversion and positive affect (e.g., Fleeson et al, 2002). The present study has further demonstrated that acting extraverted in the moment is linked with an increase in positive mood, regardless of underlying introversion-extraversion disposition. McNiel and Fleeson (2006) suggested that showing a relationship between state extraversion and positive affect lends support to clinical interventions, suggesting that individuals with clinical disorders could be coached to act more extraverted in order to improve their well being. In the present study, it is clear that in a social situation, following instructions to act extraverted is better for one's affective state than following instructions to act introverted; however, it is unclear if this is better than simply engaging in a social situation.

Before behavioural interventions are implemented, it is important to first assert that there is more benefit received from the behaviour than the behaviour already exhibited by the individual. As well, it is important to ascertain that the benefits of acting extraverted 
outweigh the costs of the behaviour. The present study offers support regarding a connection between one's cognitive state and behavioural state. The marginally significant findings have revealed that individuals who acted out of character in terms of introversion-extraversion disposition showed signs of ego depletion on a behavioural measure. More specifically, it appeared that introverted individuals in the extraverted condition, who received the beneficial increase in positive affect, showed signs of depletion. The pattern of the results suggests that acting extraverted may require regulation for introverts and, therefore, may produce a state of cognitive fatigue. This is in line with the notion presented by the Free Trait Model that acting counter to one's genetic disposition is met with costs. Although the findings were not supported by the physiological measure, processes involving glucose are not yet fully understood. As well, glucose has not conclusively been shown to be a reliable and valid measure of selfregulation across studies.

No definitive conclusions can be drawn from the findings, but the results of the present study are promising. If self regulating behaviour to act more extraverted leads to a state of ego depletion, then the costs associated with the behaviour could have wideranging consequences. With a vast number of daily activities relying on self-regulatory ability, depleting one's resource can lead to impairments in other areas of one's life. Before extraverted behaviour is used in clinical intervention to increase well-being, it is essential to understand the costs that may be associated with doing so. 


\section{References}

Allen, J. B., Gross, A. M., Aloia, M. S., \& Billingsley, C. (1996). The effects of glucose on nonmemory cognitive functioning in the elderly. Neuropsychologia, 34 (5), $459-465$.

Argyle, M., \& Lu, L. (1990). The happiness of extraverts. Personality and Individual Differences, 11, 1011-1017.

Ashby, F. G., Isen, A. M., \& Turken, U. (1999). A neuropsychological theory of positive affect and its influences on cognition. Psychological Review, 106 (3), 529-550.

Augustine, A. A., Hemenover, S. H. (2008). Extraversion and the consequence of social interaction on affect repair. Personality and Individual Differences, 44, 11511161.

Baumeister, R. F., \& Heatherton, T. F. (1996). Self-regulation failure: An overview. Psychological Inquiry, 7 (1), 1-15.

Baumeister, R. F., Bratslasvky, E., Muraven, M., \& Tice, D. M. (1998). Ego depletion: Is the active self a limited resource? Journal of Personality and Social Psychology, $74(5), 1252-1265$.

Baumeister, R. F., Heatherton, T. F., \& Tice, D. M. (1993). When ego threats lead to selfregulation failure: Negative consequences of high self-esteem. Journal of Personality and Social Psychology, 64 (1), 141-156.

Baumeister, R. F. (2002). Ego-depletion and self-control failure: An energy model of the self's executive function. Self and Identity, 1, 129-136. 
Baumeister, R. F., DeWall, C. N., Ciarocco, N. J., \& Twenge, N. J. (2005). Social exclusion impairs self-regulation. Journal of Personality and Social Psychology, $88(4), 589-604$.

Baumeister, R. F., Vohs, K. D., \& Tice, D. M. (2007). The strength model of self-control. Current Directions in Psychological Science, 16 (6), 351-355.

Baumeister, R. F., Gailliot, M., DeWall, C. N., \& Oaten, M. (2006). Self-regulation and personality: How interventions increase regulatory success, and how depletion moderates the effects of traits on behavior. Journal of Personality, 74 (6), 17731801.

Benton, D. (1990). The impact of increasing blood glucose on psychological functioning. Biological Psychology, 30, 13-19.

Benton, D., Brett, V., \& Brain, P. F. (1987). Glucose improves attention and reaction to frustration in children. Biological Psychology, 24, 95-100.

Benton, D. \& Owens, D. S. (1993). Is raised blood glucose associated with the relief of tension? Journal of Psychosomatic research, 37 (7), 723-735.

Benton, D., Owens, D. S., \& Parker, P. Y. (1994). Blood glucose influences memory and attention in young adults. Neuropsychologia, 32 (5), 595-607.

Booth, D. (1994). The psychology of nutrition. London: Taylor and Francis.

Costa, P. T. \& McCrae, R. R. (1980). Influence of extraversion and neuroticism on subjective well-being: Happy and unhappy people. Journal of Personality and Social Psychology, 38, 668-678. 
Costa, P. T., \& McCrae, R. R. (1988). Personality in adulthood: A six-year longitudinal study of self-report and spouse ratings on the neo personality inventory. Journal of Personality and Social Psychology, 54, 853-863.

Côté, S., \& Moskowitz, D. S. (1998). On the dynamic covariation between interpersonal behavior and affect: Prediction from neuroticism, extraversion, and agreeableness. Journal of Personality and Social Psychology, 75 (4), 1032-1046.

Craft, S., Murphy, C., \& Wemstrom, J. (1994). Glucose effects on complex memory and nonmemory tasks: The influence of age, sex, and glucoregulatory response. Psychobiology, 22 (2), 95-105.

Crockett, L. J., Raffaelli, M., \&Shen, Y. (2006). Linking self-regulation and risk proneness to risky behavior: Pathways through peer pressure and early substance use. Journal of Research on Adolescence, 16 (4), 503-525.

DeWall, C. N., Baumeister, R. F., Stillman, T. F., \& Gailliot, M. T. (2007). Violence restrained: Effects of self-regulation and its depletion on aggression. Journal of Experimental Social Psychology, 43, 62-76.

DeWall, C. N., Vohs, K. D., \& Baumeister, R. F. (2008). Satiated with belongingness? Effects of acceptance, rejection, and task framing on self-regulatory performance. Journal of Personality and Social Psychology, 95 (6), 1367-1382.

Diener, E., \& Larsen, R. J., \& Emmons, R. A. (1984). Person x situation interaction: Choice of situations and congruence response models. Journal of Personality and social Psychology, 47, 580-592.

Donohoe, R. T., \& Benton, D. (1999). Cognitive functioning is susceptible to the level of blood glucose. Psychophramacology, 145, 378-385. 
Donohoe, R. T., \& Benton, D. (2000). Glucose tolerance predicts performance on tests of memory and cognition. Physiology \& Behavior, 71 (3-4), 395-401.

Dragutinovich, S. (1987). Stimulus intensity reducers: Are they sensation seekers, extraverts, and strong nervous types? Personality \& Individual Differences, 8 (5), 693-704.

Eisenberg, N., Spinrad, T. L., \& Morris, A. S. (2002). Regulation, resiliency, and quality of social functioning. Self and Identity, 1, 121-128

Fairclough, S. H., \& Houston, K. (2004). A metabolic measure of mental effort. Biological Psychology, 66, 177-190.

Ferrari, J. R. \& Pychyl, T. A. (2007). Regulating speed, accuracy and judgments by indecisives: Effects of frequent choices on self-regulation depletion. Personality and Individual Differences, 42, 777-787.

Fibiger, W., Evans, O., \& Singer, G. (1986). Hormonal responses to graduated mental workload. European Journal of Applied Physiology, 55, 339-343.

Fischer, H., Wik, G., \& Frederikson, M. (1997). Extraversion, neuroticism, and brain function: A pet study of personality. Personality and Individual Differences, 23 (2), 345-352.

Fleeson, W. (2001). Toward a structure- and process-integrated view of personality: Traits as density distributions of states. Journal of Personality and Social Psychology, 80 (6), 1011-1027.

Fleeson, W. (2004). Moving personality beyond the person-situation debate: The challenge and opportunity of within-person variability. Current Directions in Psychological Science, 13(2), 83-87. 
Fleeson, W. (2007) Situation-based contingencies underlying trait-content manifestation in behavior. Journal of Personality, 75 (4), 826-861.

Fleeson, W., Malanos, A. B., \& Achille, N. M. (2002). An intraindividual process approach to the relationship between extraversion and positive affect: Is acting extraverted as "good" as being extraverted? Journal of Personality and Social Psychology, 83 (6), 1409-1422.

Folkman, S. \& Moskowitz, J. T. (2000). Positive affect and the other side of coping. American Psychologist, 55 (6), 647-654.

Fry, S. K., \& Heubeck, B. G. (1998). The effects of personality and situational variables on mood states during outward bound wilderness courses: An exploration. Personality and Individual Differences, 24 (5), 649-659.

Frederickson, B. L. \& Joiner, T. (2002). Positive emotions trigger upward spirals toward emotional wellbeing. Psychological Science, 13 (2), 172-175.

Fredrickson, B. L., \& Losada, M. F. (2005). Positive affect and the complex dynamics of human flourishing. American Psychologist, 60 (7), 678-686.

Gailliot, M. T., Baumeister, R. F., DeWall, C. N., Maner, J. K., Plant, E. A., Tice, D. M., Brewer, L. E., \& Schmeichel, B. J. (2007). Self-control relies on glucose as a limited energy source: Willpower is more than a metaphor. Journal of Personality and Social Psychology, 92 (2), 325-336.

Gailliot, M. T., Plant, E. A., Butz, D. A., \& Baumeister, R. F. (2008). Increasing selfregulatory strength can reduce the depleting effect of suppressing stereotypes. Personality and Social Psychology Bulletin, 33 (2), 281-294. 
Gailliot, M. T., \& Baumeister, R. F. (2007). The physiology of willpower: Linking blood glucose to self-control. Personality and Social Psychology Review, 11 (4), 303327.

Gailliot, M. T. (2008). Unlocking the energy dynamics of executive functioning: Linking executive functioning to brain glycogen. Perspectives on Psychological Science, 3 (4), 245-263.

Glass, D. C., Singer, J. E., \& Friedman, L. N. (1969). Psychic cost of adaptation to an environmental stressor. Journal of Personality and Social Psychology, 12, 200210.

Glass, D. C., \& Singer, J. E. (1972). Urban stress: Experiments on noise and social stressors. New York: Academic Press.

Goldberg, L. R. (1992). The development of markers for the big-five factor structure. Psychological Assessment, 4 (1), 26-42.

Gray, J. A. (1981). A critique of Eysenck's theory of personality. In H. J. Eysenck (Ed.), A model for personality (pp. 246-276). Berlin: Springer-Verlag.

Green, M. W., Elliman, N. A., \& Rogers, P. J. (1997). The effects of food deprivation and incentive motivation on blood glucose levels and cognitive fatigue. Psychopharmacology, 134, 88-94.

Headey, B., \& Wearing, A. (1989). Personality, life, events, and subjective well-being: Toward a dynamic equilibrium model. Journal of Personality and social Psychology, 57, 731-739.

Heatherton, T. F. \& Baumeister, R. F. (1996). Self-regulation failure: Past, present, and future. Psychological Inquiry, 7 (1), 90-98. 
Hoyle, R. H. (2006). Personality and self-regulation: Trait and information-processing perspectives. Journal of Personality, 74 (6), 1507-1526.

Isen, A. M., Daubman, K. A., 9\& Nowicki, G. P. (1987). Positive affect facilitates creative problem solving. Journal of Personality and Social Psychology, 52 (6), $1122-1131$.

Jarrett, R. J. (1979). Rhythms in insulin and glucose. In T. T. Krieger (Ed.), Endocrine rhythms (pp.247-258). New York: Raven.

Kennedy, D. O., \& Scholey, A. B. (2000). Glucose administration, heart rate and cognitive performance: Effects of increasing mental effort. Psychopharmacology, $149,63-71$.

Kennedy, D. O., \& Scholey, A. B. (2004). A glucose-caffeine 'energy drink' ameliorates subjective and performance deficits during prolonged cognitive demand. Appetite, 42, 331-333.

Kuk, G. (2000). "When to speak again": Self-regulation under facilitation. Group Dynamics: theory, Research, and Practice, 4 (4), 291-306.

Larsen, R. J. \& Ketelaar, T. (1991). Personality and susceptibility to positive and negative emotional states. Journal of Personality and Social Psychology, 61 (1), $132-140$.

Leary, M. R., Nezlek, J. B., Downs, D., Radford-Davenport, J., Martin, J., \& McMullen, A. (1994). Self-presentation in everyday interactions: Effects of target familiarity and gender composition. Journal of Personality and Social Psychology, 67, 664673. 
Little, B. R. (2000). Free traits and personal contexts: Expanding a social ecological model of well-being. In W. B. Walsh, K. H. Craik \& R. H. Price (Eds.), Personenvironment psychology: New directions and perspectives (2nd ed., pp. 87-116). Mahwah, NJ: Lawrence Erlbaum Associates.

Little, B. R. (2006). Personality science and self-regulation: Personal projects as integrative units. Applied Psychology: An International Review, 55 (3), 419-427.

Little, B. R., \& Joseph, M. F. (2007).Personal projects and free traits: Mutual selves and well beings. In B. R. Little, K. Salmela-Aro \& S. D. Phillips (Eds.), Personal Project Pursuit: Goals, Action, and Human Flourishing (1st ed., pp. 375- 400). Mahwah, NJ: Lawrence Erlbaum Associates.

Lolas, F., Camposano, S, \& Etcheberrigaray, R. (1989). Augmenting/reducing and personality: A psychometric and evoked potential study in a chilean sample. Personality \& Individual Differences, 10 (11), 1173-1176.

Lorist, M. M., Boksem, M. A. S., \& Ridderinkhof, K. R. (2005). Impaired cognitive control and reduced cingulated activity during mental fatigue. Cognitive Brain Research, 24, 199-205.

Lucas. R. E. \& Fujitas, F. (2000). Factors influencing the relation between extraversion and pleasant affect. Journal of Personality and Social Psychology, 79 (6), 10391056.

Lucas, R. E., Le, K., \& Dyrenforth, P. S. (2008). Explaining the extraversion/positive affect relation: Sociability cannot account for extraverts' greater happiness. Journal of Personality, 76 (3), 385-414. 
Lustman, P. J., Frank, B L., \& McGill, J. B. (1991). Relationship of personality characteristics to glucose regulation in adults with diabetes. Psychosomatic Medicine, 53, 305-312.

Lyubomirsky, S., Diener, E., King, L. (2005). The benefits of frequent positive affect: Does happiness lead to success? Psychological Bulletin, 131 (6), 803-855.

Magistretti, P. J., Pellerin, L., Rothman, D. L., \& Shulman, R. G. (1999). Energy on demand. Science, 354, 496-497.

Markus, C. R. (2007). Effects of carbohydrates on brain tryptophan availability and stress performance. Biological Psychology, 76, 83-90.

Matthews, D. R., Holeman, R. R., Bown, E., Steenson, J., Watson, A., Hughes, S., \& Scott, D. (1987). Pen-sized digital 30-second blood glucose meter. Lancet, 1, 778779.

McIntyre, C. W., Watson, D., Clark, L. A., \& Cross, S. A. (1991). The effect of induced social interaction on positive and negative affect. Bulletin of the Psychonomic Society, $29(1), 67-70$.

McNiel, J. M. \& Fleeson, W. (2006). The causal effects of extraversion on positive affect and neuroticism on negative affect: Manipulating state extraversion and state neuroticism in an experimental approach. Journal of Research in Personality, 40, 529-550.

Meikle, A., Riby, L. M., \& Stollery, B. (2004). The impact of glucose ingestion and gluco-regulatory control on cognitive performance: A comparison of younger and middle aged adults. Human Psychopharmacology, 19, 523-535. 
Muraven, M. and Baumeister, R. (2000). Self-regulation and depletion of limited resources: Does self-control resemble a muscle? Psychological Bulletin, 126 (2), 247-259.

Muraven, M., Tice, D., \& Baumeister, R. (1998). Self-control as limited resource: Regulatory depletion patterns. Journal of Personality and Social Psychology, 74 (3), 774-789.

O’Hanlon, J. F., \& Horvath, S. M. (1973). Interrelationships among performance, circulating concentrations of adrenaline, noradrenaline, glucose, and free fatty acids in men performing a monitoring task. Psychophysiology, 10 (3), 251-259.

Owens, D. S., Parker, P. Y., \& Benton, D. (1997). Glucose and subjective energy following cognitive demand. Physiology \& Behavior, 62 (3), 471-478.

Pavot, W., Diener, E., \& Fujita, F. (1990). Extraversion and happiness. Personality and Individual Differences, 11 (12), 1299-1306.

Petrie, A. (1967). Individuality in Pain and Suffering. Chicago: University of Chicago Press.

Pettit, J.W., Kline, J. P., Gencoz, T., Gencoz. F., \& Joiner, T. E. (2001). Are happy people happier? The specific role of positive affect in predicting self-reported health symptoms. Journal of Research in Personality, 35, 521-536.

Rusting, C. L., \& Larsen, R. J. (1995). Moods as sources of stimulation: relationships between personality and desired mood states. Personality and Individual Differences, 18 (3), 321-329. 
Rusting, C. L. \& Larsen, R. J. (1997). Extraversion, neuroticism, and susceptibility to positive and negative affect: A test of two theoretical models. Personality and Individual Differences, 22 (5), 607-612.

Santoro, M. (2007). Why acting extraverted may not be as good as being extraverted: An investigation into a potential cost of behaving in a counter-dispositional manner. Unpublished bachelor's dissertation, Carleton University, Ottawa.

Saucier, G. (1994). Mini-markers: A brief version of goldberg's unipolar big-five markers. Journal of Personality Assessment, 63 (3), 506-516.

Schmeichel, B. J., Baumeister, R. F., \& Vohs, K. D. (2003). Intellectual performance and ego depletion: Roles of the self in logical reasoning and other information processing. Journal of Personality and Social Psychology, 85 (1), 33-46.

Scholey, A. B., Kennedy, D. O. (2004). Cognitive and physiological effects of an "energy drink": an evaluation of the whole drink and of glucose, caffeine and herbal flavouring fractions. Psychopharmacology, 176, 320-330.

Scholey, A. B., Harper, S., \& Kennedy, D. O. (2001). Cognitive demand and blood glucose. Physiology \& Behavior, 73, 585-592.

Schwerdtfeger, A., Getzmann, S., \& Baltissen, R. (2004). Fast reducers, slow augmenters: A psychophysiological analysis of temperament-related differences in reaction time. International Journal of Psychophysiology, 52, 225-237.

Stenberg, G., Rosen, I., \& Risenberg, J. (1988). Personality and augmenting/reducing in visual and auditory evoked potentials. Personality \& Individual Differences, 9 (3), 571-579. 
Sunram-Lea, S. I., Foster, J. K., Durlach, P., \& Perez, C. (2001). Glucose facilitation of cognitive performance in healthy young adults: Examination of the influence of fast-duration, time of day and pre-consumption plasma glucose levels. Psychopharmacology, 157, 46-54.

Van der Linden, D., Frese, M., \& Meijman, T. F. (2003). Mental fatigue and the control of cognitive processes: Effects on perseveration and planning. Acta Psychologica, $113,45-65$.

Vohs, K. D., Ciarocco, N. J., \& Baumeister, R. F. (2005). Self-regulation and selfpresentation: Regulatory resource depletion impairs impression management and effortful self-presentation depletes regulatory resources. Journal of Personality and Social Psychology, 88 (4), 632-657.

Watson, D. (1988). Intraindividual and interindividual analyses of positive and negative affect: Their relation to health complaints, perceived stress, and daily activities. Journal of Personality and Social Psychology, 54 (6), 1020-1030.

Watson, D., Clark, L. A., \& Tellegen, A. (1988). Development and validation of the brief measures of positive and negative affect: The panas scales. Journal of Personality and Social Psychology, 54 (6), 1063-1070.

Weiss, A., King, J. E., \& Enns, R. M. (2002). Subjective well-being is heritable and genetically correlated with dominance in chimpanzees (pan troglodytes). Journal of Personality and Social Psychology, 83, 1141-1149.

Williams, C. (2006). An Investigation of the Self-Regulatory Costs Associated with Manipulating State Extraversion. Unpublished bachelor's dissertation, Carleton University, Ottawa. 
Wilson, K., \& Gullone, E. (1999). Predicting the future: How affect-related personality traits influence likelihood judgments of future events. Personality and Social Psychology Bulletin, 28, 1000-1010.

Wredling, R. A. M., Theorell, P. G. T., Roll, M. H., Lins, P. E. S., \& Adamson, U. K. C. (1992). Psychosocial state of patients with IDDM prone to recurrent episodes of severe hypoglycemia. Diabetes Care, 75, 518-521. 
Appendix A- Mass Testing Questionnaire

\begin{tabular}{|l|l|l|l|}
\hline Name: & & & \\
\hline Student \#: & & & \\
\hline $\begin{array}{l}\text { Email } \\
\text { address: }\end{array}$ & & & \\
\hline Phone \#: & & & \\
\hline
\end{tabular}

HOW ACCURATELY CAN YOU DESCRIBE YOURSELF?

Please use this list of common human traits to describe yourself as accurately as possible. Describe yourself as you see yourself at the present time, not as you wish to be in the future. Describe yourself as you are generally or typically, as compared with other persons you know of the same sex and of roughly your same age.

Before each trait, please write a number indicating how accurately that trait describes you, using the following rating scale:

Not At

All

1
Somewhat

4
Very

Well

3

5

6

Bashful

Bold

Energetic

Envious

Extraverted

Fretful

Jealous

Moody
Quiet

Relaxed

Shy

Talkative

Temperamental

Touchy

Unenvious

Withdrawn 


\section{Appendix B- Informed Consent Form}

The purpose of an informed consent is to insure that you understand the purpose of the study and the nature of your involvement. The informed consent must provide sufficient information such that you have the opportunity to determine whether you wish to participate in the study.

Present study: Personality Impressions

Research personnel. The following people are involved in this research project and may be contacted at any time: Dr. J. Zelenski (Faculty Sponsor, 520-2600 ext. 1609) or Maya Santoro (email: msantoro@connect.carleton.ca). Should you have any ethical or other concerns about this study then please contact Dr. Avi Parush, Chair, Carleton University Ethics Committee for Psychological Research, (520-2600, ext. 6026) or Dr. Janet Mantler (Chair, Dept. of Psychology, 520-2600, ext. 2648).

Purpose. The purpose of this study is to examine the relationship between personality impressions, physiology, and cognition.

Task requirements. The experiment is split into a few different types of tasks. In the first task, you will partake in a casual interview where you will be asked to answer questions about yourself. This interaction will be video taped. This will be followed a package of questionnaires on your reactions. In the second task, you will be asked to complete an individual computer or paper-based problem-solving task. Following this, you will be asked to complete one more questionnaire. The videotaped recording is confidential and will not be attached to your name. It may be reviewed by a researcher. After the study has been completed, the videotaped recording will be securely stored. As well, two glucose measurements will be collected.

Duration and locale. The session will last about 75 minutes and experimental testing will take place in the Human Computer Interaction Building.

What you will receive. You will receive $1.5 \%$ increase in your final grade for participating. * $\$ 10$ compensation can be obtained in place of the $1.5 \%$ increase. As well, you will receive the chance to win $\$ 200.00$ in a draw. This is a random draw that is not related to your performance in the study. The draw will take place on December $7^{\text {th }}$ and the odd of winning are approximately 1 in 100 .

Potential risk/discomfort. Two blood samples will be collected from the tip of your finger. This process may cause some discomfort, although minimal. You may find one of the tasks difficult, but it is unlikely that this discomfort will exceed that which people experience in day-to-day life. The sample will be used to measure glucose level and is commonly used in diabetic populations. The sample will be destroyed after collection.

Anonymity/confidentiality. The data collected in this experiment are strictly confidential. All data are coded such that your name is not associated with the data. In addition, the coded data are made available only to the researchers associated with this project.

Right to withdraw. You may withdraw from the study at any time without academic penalty. You may also choose to skip (i.e., not answer) questions you find objectionable for any reason without penalty. 
Signatures

I have read the above form and understand the conditions of my participation. My participation in this study is voluntary, and if for any reason, at any time, I wish to leave the experiment I may do so without having to give an explanation and with no penalty whatsoever. Furthermore, I am also aware that the data gathered in this study are confidential and anonymous with respect to my personal identity. My signature indicates that I agree to participate in the study.

Participant's Name: Participant's Signature:

Researcher's Name: Researcher's Signature:

Date 
Appendix C- Debriefing Sheet

\section{Group Problem Solving: Debriefing Sheet}

\section{What are we trying to learn in this research?}

Recent research has suggested that acting extraverted is related to heightened positive emotions. This relationship is found for both dispositional extraverts and introverts. This project aims to understand costs associated with acting out of character for introverts who are instructed to act extraverted. We predict that people will experience stronger positive emotions when acting extraverted compared to introverted. However, there may be psychological costs associated with acting in a counter dispositional manner. More specifically, high-arousal unpleasant affect may increase, and cognitive fatigue may arise from acting out of character.

Mass Testing provided your trait extraversion score. Some participants who come into this study are asked to behave in a particular manner during the interview situation (extraverted or introverted). This served as a manipulation of state personality. The questionnaires you completed assessed personality states and mood. The individual problem-solving task and glucose measurements tested cognitive fatigue. This study allows us to examine the relationship between personality traits, personality states, affect, and cognitive fatigue.

\section{Why is this important to scientists or the general public?}

There is strong evidence for a link between the trait of extraversion and positive affect. More current research has demonstrated that acting extraverted is also linked with an increase in positive mood. We would like to determine if there are psychological costs to regulating one's personality. More specifically, this study is examining negative affect, stress, and cognitive fatigue potential costs associated with acting counter to one's personality disposition. This may be important to understanding why some people are happier than others.

\section{Where can I learn more?}

You may want to look at the following article as an example of how personality, emotion, and cognition combine:

Fleeson, W., Malanos, A. B., \& Achille, N. M. (2002). An intraindividual process approach to the relationship between extraversion and positive affect. Is acting extraverted as "good" as being extraverted? Journal of Personality and Social Psychology, 83, 1409-1422.

\section{What if I have questions later?}

If you have any remaining concerns, questions, or comments about the experiment please feel free to email Maya Santoro (msantoro@connect.carleton.ca) or speak to Dr. John Zelenski (520-2600 $\mathrm{x} 1609$ ). If you have any ethical concerns you can also discuss them with Dr. Avi Parush, Chair, Carleton University Ethics Committee for Psychological Research, 520-2600, ext. 6026) or Dr. Janet Mantler (Chair, Dept. of Psychology, 520-2600, ext. 2648). 
Hi there,

\section{Appendix D- Email for Recruitment}

In the Fall semester, you participated in mass testing and have been selected to be invited to participate if our study entitled Personality Impressions. We are currently conducting a study about personality impressions, physiology, and cognition. The study takes approximately 75 minutes to complete and you would receive $1.5 \%$ increase in grade for participating. $* \$ 10$ compensation can be obtained in place of the $1.5 \%$ increase. As well, all participants have a 1 in 100 chance to win $200 \$$ at the end of the term. This is a random draw that is not related to your performance in the study.

The experiment is split into a few different types of tasks. In the first task, you will partake in a casual interview where you will be asked to answer questions about yourself. This interaction may be video taped. This will be followed a package of questionnaires on your reactions. In the second task, you will be asked to complete an individual computer or paper-based problemsolving task. At two points during the study, a sample of blood will be taken from the tip of your finger. This process may cause minor discomfort, but is virtually pain free. In order to get an accurate reading from the blood sample, we would also ask that you do not eat or drink for 3 hours before participation in the study.

If you would like to participate in this study, please follow the link provided below.

Note: If you have not used the Experimental Sign-up System before, you will need to register in the system. This should only take a few minutes and will allow you to participate in other studies using the system.

http://carleton.sona-systems.com

Once you reach the website the system will ask you to enter your User ID and Password. Again, if you are a new user, you will need to set this up first. Once you have entered your User ID and Password, go to the study called "Personality Impressions". Once you select this study the system will prompt you to enter a password. The password for this experiment is "personality". The system will now permit you to sign up for one of the scheduled experiment time slots listed.

Experiment Password: personality

This experiment will take place in the HCI building room 6111. The HCI building is located beside Loeb, (http://www.carleton.ca/cu/campus/ for link to campus map).

Thank you very much. Your participation is extremely valuable and appreciated. Maya Santoro cuhllab@yahoo.ca; 520-2600 ext.1813 
Appendix E- Demographics Questionnaire

\section{DEM}

Part id:

1. Sex: MALE

FEMALE (please circle one)

2. Age:

3. Do you have any health conditions (e.g., allergies, Type 1 or 2 diabetes, glucose intolerance, etc.)?

1. Have you eaten in the last 3 hours?

YES

NO

a. If YES, what did you eat? 
Appendix F- Interview Instructions

You will be participating in an interview session with another participant for approximately 20 minutes.

During this interview, we would like you to act in a particular way. Please try your best to act in that way.

Specifically, we would like you to be bold, talkative, energetic, active, assertive, and adventurous. During the entire interview, please try to act in those ways.

Begin acting bold, talkative, energetic, active, assertive, and adventurous when you leave this room to have your interview and continue to act in the manner described until you return to this room.

This may or may not be the way you normally act - that is ok. Just please try to act in those ways as much as possible during the entire interview. Don't lie, but emphasize these aspects of yourself.

Interview situations are common occurrences in every day life and we hope to better understand the way in which people perceive each other in an interview situation.

Please do not discuss your instructions with the other participant. 
Appendix G- Interview Instructions

You will be participating in an interview session with another participant for approximately 20 minutes.

During this interview, we would like you to act in a particular way. Please try your best to act in that way.

Specifically, we would like you to be reserved, quiet, lethargic, passive, compliant, and unadventurous. During the entire interview, please try to act in those ways.

Begin acting reserved, quiet, lethargic, passive, compliant, and unadventurous when you leave this room to have your interview and continue to act in the manner described until you return to this room. Don't lie, but emphasize these aspects of yourself.

This may or may not be the way you normally act - that is ok. Just please try to act in those ways as much as possible during the entire interview.

Interview situations are common occurrences in every day life and we hope to better understand the way in which people perceive each other in an interview situation.

Please do not discuss your instructions with the other participant. 
Appendix H- Interview Instructions

You will be participating in an interview session with another participant for approximately 20 minutes.

We are interested in first impressions, in particular in an interview situation. Act naturally.

Interview situations are common occurrences in every day life and we hope to better understand the way in which people perceive each other in an interview situation.

Please do not discuss your instructions with other participant. 


\section{Appendix I- Interview Questions \\ Questions for Interview}

1. What is your name/age?

2. Where are you from?

3. What is your major? How did you come to choose it?

4. What do you like/dislike about your major?

5. What do you like to do for fun?

6. What kind of music do you like?

7. If you had a million dollars, what would you do with it?

8. If you could have any job, what would it be and why?

9. What are some of your favourite movies? What do you like about them?

10. Do you like to read? Which types of books do you prefer?

11. Do you have preferred seasons? Why?

12. Do you have a vivid imagination? Why do you say that?

13. What do you like to do on the weekends?

14. If you were on a desert island, and could have three items with you, what three items would you have?

15. What is the most adventurous thing you have done?

16. Do you consider yourself more of a leader or a team player? Does it depend on where you are?

17. Do you find that you procrastinate with your schoolwork often? What do you do when you procrastinate?

18 . Would you classify yourself as an impulsive person? Why/why not?

19. Do you watch television? If so, what are your favourite shows and why?

20. Would you say that you are a competitive person? If so, in what areas of your life do you tend to compete most with others?

21. Are you a perfectionist? In what areas of your life?

22. Tell me about a time when you were (happy, proud, etc.)

23. What does a typical day for you consist of?

24. What are you optimistic about? What are you pessimistic about?

25 . Have you ever traveled before?

- If yes, where have you been? What is your favourite place? Least favourite place? Why?

- If no, where would you like to travel most? Least?

26. What are your favourite foods? Why?

27. What are your least favourite foods? Why?

28. If you could spend a day with a famous person, either living or dead, who would it be?

- Why?

- What would you do?

29. Do you have a special talent?

- If yes, Tell me about it

30. If you could have any talent in the world what would you have and why? 


\section{Appendix J- PANAS}

\section{Emotions}

This scale consists of a number of words that describe different feelings and emotions. Read each item and then mark the appropriate answer in the space next to that word. Indicate to what extent you have felt this way during the interview. Use the following scale to record your answers:

\begin{tabular}{|c|c|c|c|c|}
\hline $\begin{array}{c}\text { Very slightly } \\
\text { or not at all } \\
1\end{array}$ & 2 & der: & 6 & $\begin{array}{c}\text { Extremely } \\
\text { or a lot } \\
7\end{array}$ \\
\hline & Strong & & Dull & \\
\hline & Irritable & & Excited & \\
\hline & Alert & & _Hostile & \\
\hline & Upset & & Jittery & \\
\hline & Active & & Interested & \\
\hline & Nervous & & _ Sad & \\
\hline & Embarrassed & & Worried & \\
\hline & Pleased & & Relaxed & \\
\hline & Stimulated & & Distressed & \\
\hline & Unhappy & & Quiet & \\
\hline & Bored & & Idle & \\
\hline & Drowsy & & Happy & \\
\hline & Calm & & Full of Energy & \\
\hline & Fearful & & _ Self-Conscious & \\
\hline & Stressed & & Uncomfortable & \\
\hline
\end{tabular}




\section{Appendix K- Behaviour Questionnaire}

\section{Behaviour}

Next to each adjective, please write the number that indicates how well the adjective describes the way you acted during the interview

Describes me during the discussion:

\begin{tabular}{|c|c|}
\hline \multicolumn{2}{|c|}{ Strongly } \\
\hline 1 & 2 \\
\hline & 1. Energetic \\
\hline & 2. Cooperative \\
\hline & 3. Efficient \\
\hline & 4. Cold \\
\hline & 5. Assertive \\
\hline & 6. Insecure \\
\hline & 7. Rude \\
\hline & 8. Extraverted \\
\hline & 9. Careless \\
\hline & 10. Talkative \\
\hline & 11. Warm \\
\hline & 12. Shy \\
\hline
\end{tabular}

Neither Agree

nor Disagree

4

5

6

Strongly

Agree

7 


\section{Appendix L- Enjoyment Questionnaire \\ Opinions About the Interview}

Please indicate your agreement with the following statements:

Strongly

Disagree

1
Neither Agree

nor Disagree

3
4
Strongly

Agree

6

1. The interview was enjoyable.

2. I learned something from the interview.

3. Given the topics and situation, the interview was as much fun as could be expected.

4. Sometimes I held back from saying something I wanted to.

5. Sometimes I said things even though they weren't really worth saying.

6. Prior to this interview, I knew the other participant very well.

7.Compared to other experiments I have been in (or what I was expecting), this interview was reasonably interesting.

8. I had moments of fun during the interview.

9. Time went very slowly for me during the interview.

10. I found the interview to be productive.

11. Frankly, I was bored throughout the entire interview.

12. I liked the interviewer/other participant.

13. The other participant/ interviewer seemed to like me. 
Appendix M- Confederate Questionnaire 1

Participant ID \#

\section{Questionnaire Package II \\ Ratings of Participant}

\section{Emotions}

Indicate to what extent that the other participant felt this way during the interview. It is okay if you are not certain, just go on what you saw.

During the interview, the other participant felt:

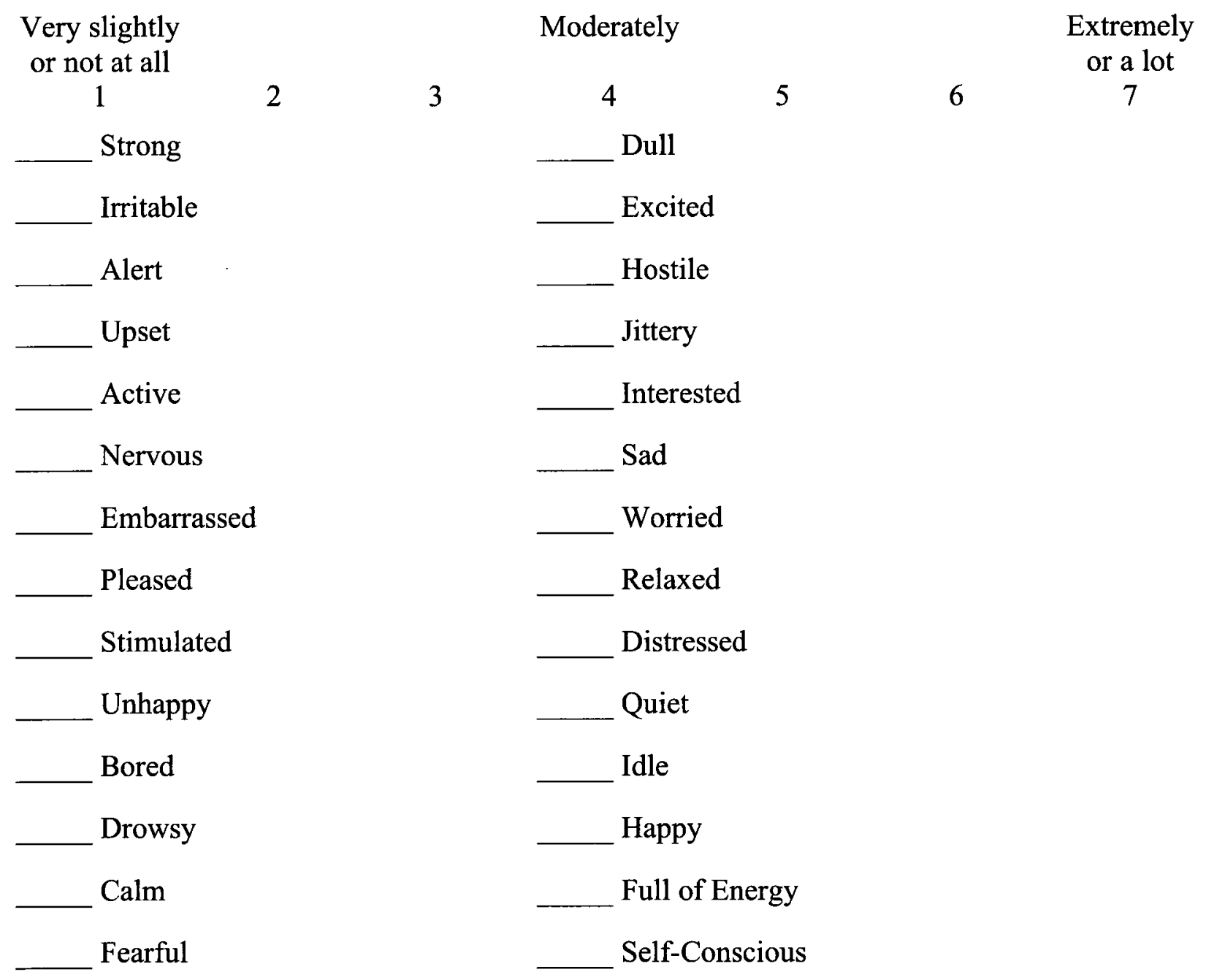




\section{Appendix N - Confederate Questionnaire 2}

\section{Ratings of Participant}

Next to each adjective, please write the number that indicates how well the adjective describes the way the other participant acted during the interview.

Describes him or her during the interview:

Strongly

Disagree

1

2

1. Energetic

2. Cooperative

3. Efficient

4. Cold

5. Assertive

6. Insecure

7. Rude

8. Extraverted

9. Careless

10. Talkative

11. Warm

12. Shy

13. Sympathetic

14. Harsh

15. Practical

16. Sloppy

17. Systematic

18. Unenvious

19. Temperamental

20. Complex

21. Relaxed

22. Uncreative

45. Deep

46. Touchy
Neither Agree

nor Disagree

4

5

6

Strongly

Agree

7

23. Kind

24. Withdrawn

25. Bold

26. Disorganized

27. Agreeable

28. Passive

29. Bashful

30. Quiet

31. Nervous

32. Adventurous

33. Considerate

34. Reserved

35. Organized

36. Imaginative

37. Inefficient

38. Unsympathetic

39. Fretful

40. Philosophical

41. Intellectual

42. Unintellectual

43. Moody

44. Jealous

47. Envious

48. Creative 